\title{
Trading rules from forecasting the collapse of speculative bubbles for the S\&P 500 composite index
}

Article

Accepted Version

Brooks, C. and Katsaris, A. (2005) Trading rules from forecasting the collapse of speculative bubbles for the S\&P 500 composite index. Journal of Business, 78 (5). pp. 20032036. ISSN 0740-9168 Available at https://centaur.reading.ac.uk/20553/

It is advisable to refer to the publisher's version if you intend to cite from the work. See Guidance on citing.

Published version at: http://www.jstor.org/stable/10.1086/431450

Publisher: University of Chicago Press

All outputs in CentAUR are protected by Intellectual Property Rights law, including copyright law. Copyright and IPR is retained by the creators or other copyright holders. Terms and conditions for use of this material are defined in the End User Agreement.

www.reading.ac.uk/centaur 
Central Archive at the University of Reading

Reading's research outputs online 
This is the authors' accepted manuscript of an article published in the Journal of Business. The definitive version is available at http://www.jstor.org/page/journal/jbusiness/about.html 


\title{
Trading Rules from Forecasting the Collapse of Speculative Bubbles for the S\&P 500 Composite Index
}

\author{
Chris Brooks, ISMA Centre, University of Reading, UK*, \\ and \\ Apostolos Katsaris, ISMA Centre, University of Reading, UK
}

\begin{abstract}
Many recent studies have documented the presence of speculative bubbles, defined as systematic and increasing deviations of actual prices from fundamentals, in asset prices. However, thus far the usefulness of such models has been examined in the literature only from a statistical perspective. In this paper we employ two-regime switching models of periodically partially collapsing speculative bubbles and examine the risk-adjusted profits of trading rules formed using inferences from them. Use of trading rules derived from an augmented model incorporating market volume leads to higher risk adjusted returns than those obtained from employing existing models or from a buy and hold strategy.
\end{abstract}

March 2004

Keywords: Stock market bubbles, regime switching, speculative bubble tests, fundamental values, trading rules.

JEL Classifications: C51, C53, G12

* Contact: Chris Brooks or Apostolos Katsaris, ISMA Centre, University of Reading, PO Box 242, Whiteknights, Reading, Berks RG6 6BA, UK Tel: (+44) 11893167 68; E-mail: C.Brooks@rdg.ac.uk or A.Katsaris@ismacentre.rdg.ac.uk We are grateful to an anonymous referee and to Ryan Davies for extensive comments on a previous version of this paper. We are also grateful to seminar participants of the Multinational Finance Society meeting in Montreal, June 2003 and to David Oakes for useful discussions. We are responsible for any remaining errors. 


\section{INTRODUCTION}

Stock prices, as well as the prices of many other traded assets, have historically shown tendencies to rise substantially over a protracted period and then to fall very quickly. At first blush, such movements in prices can be hard to reconcile with notions of investor rationality and market efficiency. However, an increasingly large literature has developed in recent years suggesting that investors acted rationally by continuing to pay ever-further inflated prices since they were being compensated for it. A persistent, systematic and increasing deviation of prices from their "fundamental value", defined as the risk-adjusted present value of all expected future cashflows, is known as a speculative bubble.

Studies of bubble behavior in asset prices can be split into two classes: direct and indirect tests. Initially, studies on the relationship between actual prices and fundamental values focused on the indirect identification of speculative bubbles in financial data (see Shiller (1981), Blanchard and Watson (1982), West (1987), Diba and Grossman (1988)). However, indirect tests of bubble presence suffered from potential problems of interpretation since bubble effects in stock prices could not be distinguished from the effects of unobservable market fundamentals. For this reason, direct bubble tests, which test directly for the presence of a particular bubble specification in stock market returns, were developed (see Flood and Garber (1980), Flood et al. (1984), Summers (1986), Cutler et al. (1991), McQueen and Thorley (1994), Salge (1997), van Norden and Schaller (1999)). Under these tests, researchers select the type of bubble that they suspect might be present in the data and then examine whether this form of speculative bubble has any explanatory power for stock market returns.

In order to examine empirically the presence of periodically collapsing bubbles, researchers 
in recent years have focused on the construction of direct bubble tests that can identify such stochastic bubble processes in financial and macroeconomic data. More specifically, Evans (1991) and van Norden and Schaller (1993) show how periodically collapsing speculative bubbles can induce regime switching behavior in asset returns. Regime switching in asset returns and speculative behavior have been linked in several studies. van Norden and Schaller (1993) and van Norden (1996) show that a two-regime speculative behavior model has significant explanatory power for stock market and foreign exchange returns during several periods of observed market over- and under-valuations. Hall et al. (1998) test for the presence of collapsing speculative bubbles in Argentinean monetary data using a univariate Markovswitching ADF test and find evidence of a speculative bubble in consumer prices in the period June 1986 to August 1988.

Research on speculative bubbles has thus far focused only on the problem of bubble identification. To our knowledge, none of the papers in the literature has examined speculative bubbles as a base for the formulation of trading strategies that exploit knowledge about the implied probability of a stock market crash. One implication of this is that the speculative bubble literature has been argued to have obvious intellectual interest but little practical value for financial market participants. In this paper, we aim to address this issue by evaluating the financial usefulness of the van Norden and Schaller (1999), hereafter vNS, regime switching model of speculative behaviour, and of an augmented version of the model including market volume proposed by Brooks and Katsaris (2002). This is achieved by examining the profitability of trading rules formed on the basis of the probabilities of a crash and of a rally in the next time period estimated from the models. 
The remainder of this paper is organised as follows. We will briefly describe the van Norden and Schaller switching regression model of periodically collapsing speculative bubbles and an augmented version of the model in Section 2. The data are also described in Section 2, with the results of model estimation presented in Section 3. Section 4 examines the forecasting ability of the augmented model and of the vNS model by looking at the profitability of trading strategies formed on the basis of inferences from these models. Section 5 concludes.

\section{REGIME SWITCHING MODELS OF PERIODICALLY COLLAPSING SPECULATIVE BUBBLES AND DATA}

vNS formulate a periodically, partially-collapsing, positive and negative speculative bubble model that has a time varying probability of collapse. They consider the following bubble process:

$$
\frac{(1+r) b_{t}}{q\left(B_{t}\right)}-\frac{1-q\left(B_{t}\right)}{q\left(B_{t}\right)} u\left(B_{t}\right) p_{t}^{a} \quad \text { with probability } q\left(B_{t}\right)
$$

$E_{t}\left(b_{t+1}\right)=$

$$
u\left(B_{t}\right) p_{t}^{a} \quad \text { with probability } 1-q\left(B_{t}\right)
$$

In (1), $B_{t}$ is the size of the bubble relative to the actual price $p_{t}^{a},\left(B_{t}=b_{t} / p_{t}^{a}\right), u\left(B_{t}\right)$ is a continuous and everywhere differentiable function such that: $u(0)=0$ and $0 \leq \partial u\left(B_{t}\right) / \partial B_{t}<1, q\left(B_{t}\right)$ is the probability of the bubble continuing to exist that is a negative function of the absolute relative size of the bubble, and $b_{t}$ is the bubble component at period $t$, defined as the difference between the actual and fundamental price at that time. Two measures of fundamentals are employed in this paper: a measure based on a multiple of 
dividends, and a measure based on Campbell and Schiller (1987); calculations using both methods are detailed in the Appendix.

As noted by Kindleberger (1989), a crash becomes more likely as the relative size of the bubble becomes larger. To incorporate this and to ensure that the estimates of the probability of survival are bounded between zero and one, vNS employ a probit specification and allow the probability of survival to depend on the relative absolute size of the bubble:

$q\left(B_{t}\right)=\Omega\left(\beta_{q, o}+\beta_{q, b}\left|B_{t}\right|\right)$

where $\Omega$ is the standard normal cumulative density function, $\Omega\left(\beta_{q, o}\right)$ is the constant probability of being in the surviving regime when the size of the bubble is equal to zero, and $\beta_{q, b}$ is the sensitivity of the probability of survival to the absolute relative size of the bubble. vNS also allow for partial bubble collapses by letting the expected bubble size in the collapsing state be a function of the relative bubble size.

The vNS model can be used in order to specify asset returns as state dependent, where the state is unobservable. This implies that the security's gross returns are given, under certain assumptions about the dividend process, by the following non-linear switching model $^{1}$ :

$$
E_{t}\left(r_{t+1} \mid W_{t+1}=S\right)=\left[M\left(1-B_{t}\right)+\frac{M B_{t}}{q\left(B_{t}\right)}-\frac{1-q\left(B_{t}\right)}{q\left(B_{t}\right)} u\left(B_{t}\right)\right] \text { with probability } \quad q\left(B_{t}\right)
$$

$$
E_{t}\left(r_{t+1} \mid W_{t+1}=C\right)=\left[M\left(1-B_{t}\right)+u\left(B_{t}\right)\right] \quad \text { with probability } \quad 1-q\left(B_{t}\right)
$$

\footnotetext{
${ }^{1}$ For a derivation of the equations, the reader is referred to the working paper version van Norden and Schaller (1997) available at the Bank of Canada web-site: http://www.bankofcanada.ca/en/res/wp97-2.htm.
} 
where $\left(r_{t+1} \mid S\right)$ denotes the gross return of period $t+1$ conditioning on the fact that the state at time $t$ is the survival state $(S)$ and on all other available information at time $t, W_{t}$ is an unobserved indicator that determines the state in which the process is at time $t, C$ denotes the collapsing state and $M$ is the gross fundamental return on the security. In order to estimate the model, vNS linearise equations (3) and (4) and derive a linear regime switching model for gross stock market returns where $\left(q\left(B_{t}\right)\right)$ is the probability of being in regime $S$ :

$r_{t+1}^{S}=\beta_{S, 0}+\beta_{S, b} B_{t}+u_{S, t+1}$

$r_{t+1}^{C}=\beta_{C, 0}+\beta_{C, b} B_{t}+u_{C, t+1}$

$P\left(W_{t+1}=S\right)=q\left(B_{t}\right)=\Omega\left(\beta_{q, 0}+\beta_{q, b}\left|B_{t}\right|\right)$

In (5), $u_{S, t+1}$ and $u_{C, t+1}$ are the unexpected gross returns of period $t+1$ in the surviving and in the collapsing regime respectively and are assumed zero mean and constant variance i.i.d. normal random variables.

Brooks and Katsaris (2002) proposed that the above model could be augmented by the inclusion of a measure of abnormal volume. Abnormal volume is argued to be employed by investors as a useful explanatory variable in determining the probability of bubble survival, and it can be considered a sign that other investors are selling the bubbly asset. Under this setting, higher volume is observed in the market simply because more and more orders are being filled because investors who already hold the asset believe the market collapse to be imminent. This increase in volume will be abnormal since it will be higher than in normal market conditions (where buy and sell orders are driven buy portfolio allocation and investment-consumption decisions) and it will be higher than during the early stages of the bubble expansion (since although volume increases, it is not as high as possible because of the reluctance of holders of the asset to sell too early). As the bubble expands and more 
investors sell because they perceive the crash to be imminent, holders of the asset will observe an ever-increasing abnormal volume and will thus be adjusting their own estimate of when the bubble will collapse even more. Once a sufficient number of investors perceive that the market no longer believes the bubble will continue to exist, they liquidate their holdings in the bubbly asset simultaneously thus causing the bubble to collapse.

The model for periodically collapsing speculative bubbles proposed by Brooks and Katsaris (2002) is thus:

$$
\frac{(1+i) b_{t}}{q\left(B_{t}, V_{t}^{x}\right)}-\frac{1-q\left(B_{t}, V_{t}^{x}\right)}{q\left(B_{t}, V_{t}^{x}\right)} u\left(B_{t}\right) p_{t}^{a} \quad \text { with probability } q\left(B_{t}, V_{t}^{x}\right)
$$

$E_{t}\left(b_{t+1}\right)=$

$$
u\left(B_{t}\right) p_{t}^{a} \quad \text { with probability } 1-q\left(B_{t}, V_{t}^{x}\right)
$$

In (6), $q\left(B_{t}, V_{t}^{x}\right)$ is the probability of the bubble continuing to exist that is a function of the relative absolute size of the bubble and the measure of abnormal volume where $\partial q\left(B_{t}, V_{t}^{x}\right) / \partial\left|B_{t}\right|<0$ and $\partial q\left(B_{t}, V_{t}^{x}\right) / \partial V_{t}^{x}<0$, and $V_{t}^{x}$ is a measure of unusual volume in period $t$. The probability of the bubble continuing to exist is a negative function of the absolute (since we allow negative bubbles to exist) size of the bubble, and of the measure of abnormal volume. Under the assumption that dividends follow a geometric random walk, we can show that the expected next period gross returns are given $b y^{2}$ :

$$
\begin{aligned}
& E_{t}\left(r_{t+1} \mid W_{t+1}=S\right)=\left[M\left(1-B_{t}\right)+\frac{M}{q\left(B_{t}, V_{t}^{x}\right)} B_{t}-\frac{1-q\left(B_{t}, V_{t}^{x}\right)}{q\left(B_{t}, V_{t}^{x}\right)} u\left(B_{t}\right)\right] \\
& E_{t}\left(r_{t+1} \mid W_{t+1}=C\right)=\left[M\left(1-B_{t}\right)+u\left(B_{t}\right)\right] \\
& P\left(r_{t+1} \mid W_{t+1}=S\right)=q\left(B_{t}, V_{t}^{x}\right)=\Omega\left(\beta_{q, 0}+\beta_{q, b}\left|B_{t}\right|+\gamma_{q, V} V_{t}^{x}\right)
\end{aligned}
$$


where $\gamma_{q, V}$ is the sensitivity of the probability of survival to the measure of abnormal volume. Note that the measure of abnormal volume affects the expected returns on the asset only indirectly through the probability of the process being in state $S$ or $C$. Abnormal volume is thus suggested to signal an increase in the size of the tails of the distribution of expected returns that would signify a higher probability of a sharp collapse in the bubble. Again, a probit model is employed for the probability of survival $\left(P\left(r_{t+1} \mid W_{t+1}=S\right)\right)$ since it satisfies the conditions set out above and it ensures that probability estimates are bounded between zero and one. In order to estimate these equations, we linearise them by taking the first order Taylor series approximation of the model around an arbitrary $B_{0}$ and $V_{0}^{x}$ and arrive at a linear switching regression model:

$$
\begin{aligned}
& r_{t+1}=\beta_{S, 0}+\beta_{S, b} B_{t}+\beta_{S, V} V_{t}^{x}+u_{t+1}^{S} \\
& r_{t+1}=\beta_{C, 0}+\beta_{C, b} B_{t}+u_{t+1}^{C} \\
& P\left(r_{t+1} \mid W_{t+1}=S\right)=q\left(B_{t}, V_{t}^{x}\right)=\Omega\left(\beta_{q, 0}+\beta_{q, b}\left|B_{t}\right|+\gamma_{q, V} V_{t}^{x}\right)
\end{aligned}
$$

where: $u_{t+1}^{S}$ is the unexpected gross return in the surviving regime and $u_{t+1}^{C}$ is the unexpected gross return in the collapsing regime. Equation (10) states that the returns in the surviving regime are a function of the relative size of the bubble and of the measure of abnormal volume. In effect, equation (10) implies that as the bubble grows, investors demand higher returns in order to compensate them for the probability of a bubble collapse and since abnormal volume signals a possible change in the long run trend in equity prices, investors want to be compensated for this risk as well. The above linear switching regression model has a probability of being in the surviving regime $P\left(r_{t+1} \mid W_{t+1}=S\right)$ that is a function of the relative

\footnotetext{
${ }^{2}$ Proof of these equations is not presented here in the interests of brevity but is available in an appendix upon
} 
size of the bubble and of the measure of abnormal volume. We estimate the augmented model under the assumption of disturbance normality using maximum likelihood to directly maximize the following log-likelihood function:

$$
\ell\left(r_{t+1} \mid \xi\right)=\sum_{t=1}^{T} \ln \left[P\left(r_{t+1} \mid W_{t+1}=S\right) \frac{\omega\left(\frac{r_{r+1}-\beta_{S, 0}-\beta_{S, b} B_{t}-\beta_{S, V} V_{t}^{x}}{\sigma_{S}}\right)}{\sigma_{S}}+P\left(r_{t+1} \mid W_{t+1}=C\right) \frac{\omega\left(\frac{r_{t+1}-\beta_{C, 0}-\beta_{C, b} B_{t}}{\sigma_{C}}\right)}{\sigma_{C}}\right]
$$

where $\xi$ is the set of parameters over which we maximize the likelihood function including $\beta_{S, 0}, \beta_{S, b}, \beta_{S, V}, \beta_{C, 0}, \beta_{C, 0}, \beta_{q, 0}, \beta_{q, B}, \gamma_{q, V}, \sigma_{S}, \sigma_{C}, \omega$ is the standard normal probability density function (pdf), $\sigma_{S}\left(\sigma_{C}\right)$ is the standard deviation of the disturbances in the surviving (collapsing) regime, and $P\left(r_{t+1} \mid W_{t+1}=C\right)=1-P\left(r_{t+1} \mid W_{t+1}=S\right)$.

Note that the maximization of this log-likelihood function produces consistent and efficient estimates of the parameters in $\xi$, as it does not require any assumptions about which regime generated a given observation. The above model is similar to the models described in Goldfeld and Quandt (1976).

From the first order Taylor series expansion, we can derive certain conditions that must hold if the periodically collapsing speculative bubble model has explanatory power for stock market returns. If the above model can explain the variation in future returns, then this would be evidence in favor of the presence of periodically collapsing speculative bubbles in the data. These restrictions are:

$$
\beta_{S, 0} \neq \beta_{C, 0}
$$


$\beta_{C, b}<0$

$\beta_{S, b}>\beta_{C, b}$

$\beta_{q, b}<0$

$\gamma_{q, V}<0$

$\beta_{S, V}>0$

Restriction (a) implies that the mean return across the two regimes is different, so that there exist two distinct regimes, although we cannot say anything about the relative size of these coefficients. Restriction (b) implies that the expected return should be negative if the collapsing regime is observed. This means that the bubble must be smaller in the following period if the bubble collapses. Note that the opposite holds for negative bubbles: the larger the negative bubble, the more positive the returns in the collapsing regime. Restriction (c) ensures that the bubble yields higher (lower) returns if a positive (negative) bubble is observed in the surviving regime than in the collapsing regime. Restriction (d) must hold since the probability of the bubble continuing to exist is expected to decrease as the size of the bubble increases. Restrictions (a) to (d) are equivalent to the restrictions derived by vNS. The additional restriction (e) must hold so that abnormally high volume signals an imminent collapse of the bubble. Finally, restriction (f) states that the coefficient on the abnormal volume measure in the state equation must be greater than zero since, as volume increases, investors perceive an increase in market risk.

We examine the power of the model to capture bubble effects in the returns of the S\&P 500 by testing the model against three simpler specifications that capture stylized features of stock market returns. These models are nested within the speculative bubble model. We repeat these tests and also examine the augmented model against the simpler vNS model 
using a likelihood ratio test. Firstly, we examine whether the effects captured by the switching model can be explained by a more parsimonious model of changing volatility. In order to test this alternative, we follow vNS and jointly impose the following restrictions:

$$
\begin{aligned}
& \beta_{C, 0}=\beta_{S, 0} \\
& \beta_{S, b}=\beta_{C, b}=\beta_{S, V}=\beta_{q, b}=\gamma_{q, V}=0 \\
& \sigma_{S} \neq \sigma_{C}
\end{aligned}
$$

Restriction (14.1) implies that the mean return across the two regimes is the same and restriction (14.2) states the bubble deviation has no explanatory power for next period returns or for the probability of being in the surviving regime. The later point suggests that there is a constant probability of being in the surviving regime as stated in restriction (14.3).

In order to separate restrictions (14.1) and (14.2), we examine whether returns can be characterized by a simple mixture of normal distributions model, which only allows mean returns and variances to differ across the two regimes. This mixture of normal distributions model implies the following restrictions:

$$
\beta_{S, b}=\beta_{C, b}=\beta_{S, V}=\beta_{q, b}=\gamma_{q, V}=0
$$

Another possible alternative is that of mean reversion in prices (fads) as described by Cutler et al. (1991). Under the fads model, returns are linearly predictable although mean returns do not differ across regimes. Furthermore, the deviation of actual prices from the fundamentals has no predictive ability for the probability of being in the surviving regime. The returns in the two regimes are characterized by different variances of residuals but are the same linear functions of bubble deviations. The fads model is thus:

$$
r_{t+1}^{S}=\beta_{0}+\beta_{b} B_{t}+u_{S, t+1}
$$


$r_{t+1}^{C}=\beta_{0}+\beta_{b} B_{t}+u_{C, t+1}$

$q_{t}=\Omega\left(\beta_{q, 0}\right)$

In the above equations, $u_{t+1} \sim N\left(0, \sigma_{S}^{2}\right)$ with probability $q_{t}, u_{t+1} \sim N\left(0, \sigma_{C}^{2}\right)$ with probability $1-q_{t}$

As a final statistical test, we also examine the robustness of our model against the more parsimonious vNS model by testing whether abnormal volume should be included in the speculative bubble model. The restrictions of this last test are:

$\beta_{S, V}=\gamma_{q, V}=0$

The data that are employed comprise 1369 monthly observations on the S\&P 500 for the period January 1888 - January 2003. The S\&P 500 prices and dividends that are used to calculate fundamental prices and gross returns are taken from Shiller ${ }^{3}$. We calculate monthly share volume by taking the sum of daily share volume reported by the NYSE for the period January 1888 - January $2003^{4}$. Unusual trading volume is defined as the percentage deviation of last month's volume from the 6 month moving average ${ }^{5}$. This moving average is constructed using only lagged volume figures that would have been included in agents' information sets. The monthly dividend and price series are transformed into real variables

\footnotetext{
${ }^{3}$ Data available at: http://www.econ.yale.edu/ shiller/data.htm. For a description of the data used see also Shiller (2000) and the description online. When the data was being gathered, Shiller's sample ended in January 2000. For this reason we updated his sample until January 2003 using data obtained from Datastream. In order to verify that the two datasets are consistent with each other, we compared Shiller's data from January 1965 to January 2000 with the values from Datastream and found no differences.

${ }^{4}$ Data available at: http://www.nyse.com/marketinfo/marketinfo.html.

${ }^{5}$ We also examined unusual trading volume measures using 3,12 and 18 month moving averages but found that the deviation from the 6-month moving average has the highest explanatory power in predicting both the level and the generating state of returns. The results for the other measures of abnormal volume are not presented for brevity and are available upon request from the authors.
} 
using the monthly U.S. Consumer Price - All Items Seasonally Adjusted Index reported in Shiller.

\section{THE RESULTS}

Figure 1 presents the bubble deviations calculated using both the dividend multiple and Campbell and Shiller approaches for the entire sample. Note that both bubble deviations are increasingly large in 1929, 1987 and the late 1990's. The bubble deviations are significantly negative in 1917, 1932, 1938, 1942 and 1982. The Campbell and Shiller measure of bubble deviations (dotted line) displays significantly more short term variability whereas the dividend multiple measure has larger and more persistent broad swings.

The results for the augmented model of speculative behavior using the dividend multiple measure of fundamental values are presented in the first panel of Table 1 alongside the results of the vNS model for comparison. The second panel of the table contains the results of the LR tests of the restrictions on the coefficients implied by the speculative bubble model while the third panel of Table 1 presents the results of the likelihood ratio (LR) tests of the simpler volatility regimes, mixture of normals, fads and vNS models.

From the first panel of Table 1, we can see that all the coefficients of the augmented model, except the bubble coefficient of the surviving equation $\left(\beta_{S, b}\right)$, have the correct sign and are of a financially meaningful magnitude. Specifically, the coefficient estimate of the intercept term in the surviving regime $\left(\beta_{S, 0}\right)$ is 1.0079 , and it is highly significant, implying that when volume is normal and the bubble size is zero, the expected return in the surviving regime is 
$0.79 \%$ per month $(9.90 \% \text { on an annual basis })^{6}$. The corresponding value of this coefficient in the vNS model is larger (1.0085), implying a return in the surviving regime when the bubble size and abnormal volume are zero of $10.69 \%$ on an annualized basis. On the other hand, the intercept coefficient in the collapsing regime equation $\left(\beta_{C, 0}\right)$ is $-3.08 \%(-31.30 \%$ annualised $)$ for the augmented model compared with $-30.35 \%$ on an annual basis for the vNS model ${ }^{7}$.

According to restriction (a), the periodically collapsing speculative bubble model implies that the intercepts across the two regimes must be statistically different from each other $\left(\beta_{S, 0} \neq \beta_{C, 0}\right)$. From the second panel of Table 1 , there are two distinct return generating regimes since the null hypothesis that the intercepts across the two regimes are the same is rejected at the $1 \%$ level ( $p$-value 0.0028$)$.

Turning to the other coefficients, although the coefficient on the relative size of the bubble in the surviving regime $\left(\beta_{S, b}\right)$ is negative ${ }^{8}$ and statistically insignificant (coefficient estimate 0.0011 with $p$-value 0.3787 ), it is greater than the corresponding coefficient in the collapsing regime ( $\beta_{C, b}=-0.0438$ ). The speculative bubble model requires the return in the collapsing regime to be a negative function of the size of the bubble $\left(\beta_{C, b}<0\right)$ while the coefficient of the bubble size in the surviving regime must be greater than the corresponding coefficient in the collapsing regime $\left(\beta_{S, b}>\beta_{C, b}\right)$. From the second panel of Table 1, the bubble coefficient in the collapsing regime is statistically smaller than zero at the 5\% level ( $p$-value of LR test

\footnotetext{
${ }^{6}$ Note that this coefficient is also statistically significantly different from 1 (p-value of $t$-test 0.0000 ).

7 These coefficients are also statistically significantly different from 1 ( $\mathrm{p}$-value of $t$-test 0.0255 for the augmented model and 0.0270 for the original vNS model).

${ }^{8}$ It is not possible to derive an expected sign for this coefficient and the speculative bubble model only implies that it should be greater in value than the bubble coefficient in the collapsing regime. Nevertheless, we should expect that as the bubble increases in size, investors demand a higher return to compensate them for the increased risk of bubble collapse.
} 
0.0273) implying that as the bubble size increases, the returns in the collapsing regime are more negative ${ }^{9}$. Furthermore, we can see that restriction (c) is satisfied since $\beta_{S, b}>\beta_{C, b}$ at the $10 \%$ level (in the second panel of Table 1 the $p$-value of the LR test 0.0369 ).

Examining the estimates of the bubble coefficients of the state equations of the vNS model we see that, again, in the surviving state the bubble coefficient is negative and statistically insignificant (-0.0002 with a $p$-value of 0.3981$)$. In the collapsing regime the bubble coefficient is smaller than in the surviving regime and is approximately equal to the augmented model estimate. This implies that if abnormal volume is zero, the two models will yield approximately the same expected returns.

However, the augmented model incorporates abnormal volume in the surviving equation. The point estimate of the abnormal volume coefficient in the surviving state $\left(\beta_{S, V}\right)$ is statistically significant ( $p$-value 0.0008), and has the expected sign according to restriction (f). The likelihood ratio test shows that the coefficient is positive at the $1 \%$ level. This implies that as volume increases, the expected returns for the next period increase, consistent with our conjecture that increased abnormal volume signals increased risk and thus investors demand a higher return. For example, in September 1929, the dividend multiple bubble deviation measure was equal to $39.25 \%$ and volume for this month was $18.30 \%$ higher than the 6 month moving average. The expected return in the surviving regime for the next time period was $0.84 \%$ for the vNS model and $0.95 \%$ for the augmented model ${ }^{10}(10.58 \%$ and $12.06 \%$ on an annual basis respectively). The expected return for the collapsing regime for the vNS model was $-4.63 \%$, while it was $-4.79 \%$ for the augmented model $(-43.41 \%$ and $-44.57 \%$ on

\footnotetext{
${ }^{9}$ The opposite holds for negative bubbles since they collapse by yielding positive abnormal returns.

${ }^{10}$ Expected returns are calculated from the point estimates of the coefficients in Table 1.
} 
an annual basis respectively). This difference in expected returns is a direct result of the inclusion of abnormal volume in the surviving state equation. The real difference of our model, however, lies in the modeling of the classifying equation that gives the probability of being in the surviving regime in the next time period.

The coefficient estimates of the classifying equation for the augmented model and for the vNS model are in favour of the presence of periodically collapsing speculative bubbles. As the bubble grows, the probability of being in the surviving regime in period $t+1$ decreases since the coefficient on the absolute bubble size is negative. For the augmented model, the intercept coefficient $\left(\beta_{q, 0}\right)$ implies that when the bubble size and the measure of abnormal volume are jointly zero, there is a $2.63 \%$ of being in the collapsing regime in the next time period. This probability is calculated as $1-\Omega\left(\beta_{q, 0}\right)$ using the point estimates shown in Table 1. The corresponding probability for the vNS model is $3.35 \%{ }^{11}$.

The point estimate of the bubble coefficient for the augmented model in the classifying equation $\left(\beta_{q, b}\right)$ is -1.3572 and is highly significant. The size of $\beta_{q, b}$, and thus the estimated probability of survival, is not very different between the two models if we examine only the relative size of the bubble. The point estimate of the abnormal volume coefficient in the probability equation $\left(\gamma_{q, V}\right)$ is negative as expected and is statistically significant $(-0.4745$ with $p$-value 0.0270$)$. Therefore, the probability of being in the collapsing regime should increase significantly prior to a bubble collapse if the augmented model is superior at forecasting regime changes. Indeed, in August 1987 the probability of collapse estimated

\footnotetext{
${ }^{11}$ Note that the unconditional average bubble size over the entire sample is $1.86 \%$ (although statistically not different from zero) and the unconditional average of the measure for abnormal volume over the entire sample is $4.79 \%$ (although statistically not different from zero as well). This implies that the average probability of being
} 
from the augmented model increases by $16.90 \%$, to a value of $7.75 \%{ }^{12}$, which is 2.95 times greater than if the size of the bubble was zero and volume was normal (2.63 times greater than the average probability of being in the collapsing regime). The vNS model estimated probability of collapse, for the same month, increases by only $7.78 \%$ to a value of $8.84 \%$, which is only 2.63 times greater than if the bubble size was equal to zero. The S\&P 500 decreased by $3.54 \%$ in the next month and by $27.47 \%$ during the next four months.

The probabilities of collapse from both models, for the dividend multiple measure of fundamental values, are presented in Figure 2. It is apparent that the augmented model yields a probability of collapse that is significantly more variable than the vNS model probability. Furthermore, the probability of being in the collapsing regime increases significantly before several bubble collapses, namely August 1929, June 1932, June 1982 and October $2000^{13}$. This implies that the augmented model, incorporating an abnormal volume measure, is helpful in timing bubble collapses.

Finally, the standard deviations of the error terms are consistent with the theory of speculative bubbles since they should have greater variance in the collapsing regime than in the surviving regime. This is because bubbles often collapse by yielding extreme negative returns (or positive returns in the case of price decreasing bubbles). The error standard deviation in the surviving regime is $3.22 \%$ while in the collapsing regime it is $10.47 \%$ on a monthly basis.

in the collapsing regime in the next time period is $2.94 \%$ for the augmented model and $3.53 \%$ for the original vNS model. 
The third panel of Table 1 presents the results of the LR tests of the augmented model against simpler models that capture well-documented properties of stock market returns. The LR test for the volatility regimes alternative rejects the volatility regimes model at the $1 \%$ level, implying either that the mean returns are different across the two regimes, or that the bubble deviation has predictive power for the returns of period $t+1$ or for the probability of being in the surviving regime. Alternatively, both of the restrictions may not be supported by the data. The test for the mixture of normal distributions separates the two restrictions and the result of the LR test shows that the data reject the mixture of normals alternative in favor of the periodically collapsing speculative bubble model. This shows that the measure of bubble deviations indeed has significant forecasting ability over the returns of the next period and the probability of residing in the surviving regime. The LR test statistic is 44.0115 , signifying rejection of the null of the mixture of normal distributions at the $1 \%$ significance level.

We also examine the augmented model against a model of simple mean reversion in S\&P 500 returns. Again, the fads model is strongly rejected in favor of the periodically collapsing speculative bubble. The implication of this rejection is that returns are a non-linear function of the bubble deviations, or that bubble deviations can help classify returns into two regimes, or both. Alternatively, the mean returns could be significantly different across the two regimes. Note that the above results are consistent with the results of vNS even in this larger sample that contains the large bubble deviations of the 1990's.

\footnotetext{
12 This probability is calculated as $1-\Omega\left(\beta_{q, 0}+\beta_{q, b}\left|B_{t}\right|+\gamma_{q, V} V_{t}^{x}\right)$ for the augmented model and $1-\Omega\left(\beta_{q, 0}+\beta_{q, b}\left|B_{t}\right|\right)$ for the vNS model using the point estimates of Table 1 .

${ }^{13}$ Some of these periods were followed by market rallies since we are also examining price-decreasing bubbles, which collapse yielding positive returns.
} 
As a final and more important statistical test, we examine whether abnormal volume has any explanatory power for the level of next period's returns and the generating state of returns. This is done by examining whether both abnormal volume coefficients are equal to zero. As seen from the third panel of Table 1, the data reject the hypothesis that the measure of abnormal volume has no explanatory or classifying power in our switching regression model at the $1 \%$ level. This shows that abnormal volume is significant in explaining expected returns and that it can be used to forecast the regime of the next time period.

In order to ensure that our model is robust to alternative specifications of fundamentals, we re-estimate the model using the bubble deviations calculated from the Campbell and Shiller measure of fundamental values. These fundamental values allow for predictable variation in the dividend price-ratio. The results for both models under this alternative fundamental specification are presented in Table 2 and are roughly unchanged. In the first panel of Table 2 we present the results of both speculative bubble models. The intercept coefficient estimates across the two regimes $\left(\beta_{S, 0}\right.$ and $\left.\beta_{C, 0}\right)$ are 1.0079 and 0.9645 respectively compared to 1.0079 and 0.9692 for the dividend multiple measure of fundamental values. The LR tests presented in the second panel of Table 2 show that restriction (a) $\left(\beta_{S, 0} \neq \beta_{C, 0}\right)$ is again supported (that is, the null hypothesis that $\beta_{S, 0}=\beta_{C, 0}$ is rejected) at the $1 \%$ level. The point estimate of the bubble coefficient in the collapsing equation $\left(\beta_{C, b}\right)$ is smaller than zero (0.0421 ) although now it is statistically significant at the 5\% level ( $p$-value 0.0393$)$. The bubble coefficient in the surviving equation $\left(\beta_{S, b}\right)$ is negative but statistically insignificant. However, the restriction that $\beta_{S, b}$ should be greater than $\beta_{C, b}$ is supported by the data (the 
null hypothesis that $\beta_{S, b}=\beta_{C, b}$ is rejected at the $5 \%$ level $)^{14}$. The results for the vNS model also show that the statistical significance of the bubble coefficients in the state equations are qualitatively unaffected if we allow for time variation in the dividend growth rate.

Moreover, under this specification of fundamentals, bubble deviations still have significant power in predicting the generating state of returns. From the results of Table $2, \beta_{q, b}$ is smaller than zero and is highly significant, as shown by the result of the $t$-test and the LR test. However, $\beta_{q, b}$ is now smaller in value $(-1.3723)$. The size of this coefficient implies that, as the absolute size of the bubble increases, the probability that the bubble will continue to exist is significantly smaller than under the previous measure of bubble deviations. This could be caused by the fact that bubble deviations calculated from the Campbell and Shiller fundamental values are smaller on average than the dividend multiple measure of bubble deviations.

More importantly, the effect and the significance of abnormal volume is unchanged and $\beta_{S, V}$ is positive and statistically significant. Furthermore, $\gamma_{q, V}$ is negative $(-0.4427)$ and statistically smaller than zero (LR test p-value 0.0270). The results show that the bubble deviations from fundamental values and the deviation of volume from the six month moving average have predictive ability for the generating state and the level of next period's returns.

Finally, the LR tests of the robustness of the speculative bubble models against stylized alternatives presented in the third panel of Table 2 show again that the augmented speculative bubble model incorporates effects that are not captured by the other, more parsimonious,

\footnotetext{
${ }^{14}$ Note that in the original vNS results, the bubble coefficient in the surviving equation was never significant,
} 
models. More significantly, the vNS LR test rejects the hypothesis that volume does not affect the levels or the generating state of future returns at the $1 \%$ level $^{15}$.

\section{PREDICTIVE AND PROFITABILITY ANALYSIS}

In the previous section, we showed that the augmented regime switching speculative bubble model has explanatory power for S\&P 500 returns. However we have said nothing about the ability of this model to forecast historical bubble collapses. In a previous study, van Norden and Vigfusson (1998) examined the size and the power of bubble tests based on regime switching models, and found that the tests are conservative, but have significant power in detecting periodically collapsing speculative bubbles. However, their technique only examines the econometric reliability of the switching speculative behavior model developed by $\mathrm{vNS}^{16}$.

In this section we will examine the out of sample forecasting ability of the augmented model and of the vNS model and investigate whether regime switching speculative bubble models can be used to create trading rules that could yield abnormal trading profits ${ }^{17}$. Although

regardless of the specification of fundamentals and the significance of the bubble coefficient in the collapsing regime diminished under the Campbell and Shiller measure of fundamental values.

${ }^{15}$ However, vNS estimate their model using part of our sample (January 1926 - December 1989). In order to directly examine the validity and statistical significance of our model, we re-estimate our model using the original vNS sample. Again, in this sub-sample the abnormal volume measure is highly significant both as a risk factor in the surviving state equation and as a classifying variable in the transition equation for both measures of fundamental values. We have also examined our model for different sub samples (namely: 1888-1926, 18881948, 1926-1954, 1954-1974, 1974-1989, 1974-2003, 1948-2003) in order to examine the robustness of the model and the results are roughly unchanged. The results for these samples are not presented here for brevity and are available from the authors upon request.

${ }^{16}$ Billio and Pelizzon (2000) use a multivariate regime switching approach to calculate accurate value at risk estimates. The speculative behavior models presented here could be used in order to construct VaR estimates for the next month.

${ }^{17}$ Note that the fundamental values and the bubble model are constructed under the assumption of constant expected rates of return and investor risk neutrality. Indeed, the ex-ante expected rate of return on the bubble is constant and equal to the expected rate of return on the bubble-free asset. For this reason it is rational for a riskneutral investor to hold the bubbly asset. However, the ex-post realised return differs from the fundamental rate 
several bubble tests have been created, to our knowledge, all of them have been targeted at the identification of bubble presence and none of them have examined whether inferences from these tests can be used in order to make financially meaningful forecasts ${ }^{18}$. This approach will also help examine the predictive ability of our model and that of the vNS model, in a financially intuitive way.

In order to ensure that the trading rules are formed using only information that is available to investors in real time, we cut the sample approximately in half, and use the data from January 1888 to December 1945 to get initial estimates of the apparent bubble deviations and of the coefficients of the augmented and vNS models. Using the point estimates of the two models, we then calculate the conditional probability of an unusually low and of an unusually high return for the next month (January 1946). We then proceed to update our sample by one observation and re-estimate the models and the probabilities of a crash and of a rally. We continue updating the sample period used by one month until the end of the sample (January 2003 ) is reached.

Note that we consider both probabilities since we allow for positive and negative bubbles, and positive (negative) bubbles collapse by yielding negative (positive) returns. Using this rolling estimation, we are able to form forecasts from the two models using only information that is available to investors up to that point in time. We then proceed to form trading rules

of return depending on which regime generates the bubble in a given period. This implies that if an investor can time the bubble collapse and sell the bubbly asset then he can earn excess returns. The investor is not able to time the bubble collapse with accuracy (if he could then a bubble could never be formed). Nevertheless, it is logical that investors sell the bubbly asset because they do not believe that the bubble will continue to exist. If investors believed that the realised return on the bubble would be forever equal to the expected rate of return on the bubble-free asset then they would never sell the bubbly asset and thus bubbles would grow for infinite time. Our trading rule is designed to show that there are 'optimal' entry and exit times from the market. 
using the inferences from both models and calculate the risk and return of the strategies each month. These trading rules are based on observation of the expected probability of a crash (rally) in the case of a positive (negative) bubble. We then evaluate the trading rules by calculating the profits (or losses) that an investor would have made if he were using the vNS model or the augmented model in an effort to time large market movements from January 1948 to January 2003 . In order to calculate the conditional probability of a crash we use the following equation:

$P\left(r_{t+1}<K\right)_{t}=q\left(r_{t+1} \mid S\right)_{t} \omega\left(\frac{K-\beta_{S, 0, t}-\beta_{S, b, t} B_{t}-\beta_{S, V, t} V_{t}^{X}}{\sigma_{u, t}}\right)+\left(q\left(r_{t+1} \mid C\right)_{t}\right) \omega\left(\frac{K-\beta_{C, 0, t}-\beta_{C, b, t} B_{t}}{\sigma_{u, t}^{C}}\right)$

where $q\left(r_{t+1} \mid S\right)_{t}=\Omega\left(\beta_{q, 0, t}+\beta_{q, b, t}\left|B_{t}\right|+\gamma_{q, V, t} V_{t}^{x}\right), q\left(r_{t+1} \mid C\right)_{t}=1-q\left(r_{t+1} \mid S\right)_{t}$, the time subscript attached to the coefficients denote the estimated values of the coefficients using data only up to and including time $t, K$ is the threshold below which a return is classified as a crash given by $K=\mu_{t}-2 *\left(\sigma_{r, t}\right), \mu_{t}$ is the mean of past gross returns until time $t, \omega$ is the standard normal probability density function, and $\sigma_{r, t}$ is the standard deviation of past gross returns until time $t$. The conditional probability of observing an extreme positive return of at least two standard deviations above the mean of past returns in period $t+1$ can be defined similarly.

The probabilities of a crash derived from the vNS model and from the augmented model for the dividend multiple measure of fundamental values are presented in Figure 3 together with markers to signify the 20 largest negative 1-month and 3-month returns observed for the S\&P $500^{19}$. In the top part of the figure, we plot the logarithm of the real S\&P 500 index and the

\footnotetext{
${ }^{18}$ Maheu and McCurdy (2000) use a Markov switching model to identify bull and bear runs in stock markets, which is able to pinpoint major market downturns, although they do not examine the model's financial usefulness.

${ }^{19}$ At this point, it should be noted that we have allowed for partial collapses in the specification of the bubble model and therefore a bubble may partially collapse for several periods before starting to grow again. For this
} 
logarithm of the dividend multiple measure of fundamental values. From Figure 3 we can see that the probability of a crash increases during several periods when a bubble is suspected to be present, but more importantly, it is high before several of the 20 largest 1-month declines of the S\&P 500. More specifically, we note that the probability of a crash increased by $19.40 \%$ in August 1987 to a value of $3.39 \%$ suggesting that a bubble collapse was likely in September 1987. The corresponding probability from the vNS model increased by only $10.65 \%$ to a value of $3.45 \%$. The average probability of a crash estimated using the augmented model for the previous year was $2.36 \%$ while for the vNS model the average probability of a crash was $2.46 \%$. Although the market did not crash until October 1987 , the market declined for four consecutive months at the end of 1987 starting in September, and thus the behavior of the probability of a crash could be taken as evidence that the augmented model times bubble collapses more sharply than the vNS model. The probability of a crash is also high in several other periods, including 1962, 1970 and 2000. All of these periods are followed by a strong correction in stock price levels.

In Figure 4, we present the conditional probability of a rally calculated from the augmented model and the vNS model alongside with markers to signify the 20 largest 1-month, 3-month and consecutive market advances ${ }^{20}$. The probability of a rally increases dramatically during several periods when a negative bubble appears to be present, especially in 1949-1950 and 1982. Again, the probability of a rally estimated from the augmented model is significantly more variable than the corresponding probability derived from the vNS model. The same conclusions can be drawn by examining the probabilities of a crash and of a rally produced

reason, we also examine the probability of a crash (rally) against the top 203 -month negative returns as well as the top 20 draw-downs. A draw-down is defined as the cumulative return from the last local maximum to the next local minimum of the S\&P 500 Index and thus refers to cumulative continuous losses. 
by the Campbell and Shiller measure of fundamental values presented in Figures 5 and 6 . The probability of a crash spikes prior to market corrections and the probability of a rally increases significantly before negative bubble collapses.

However, we can see that there are several periods during which both probabilities increase simultaneously, thus damping the effects we seek to observe - namely, the conditional probability of a crash and of a rally in the next period. This is because the conditional distribution of expected returns is a mixture of a low variance (surviving state) and a high variance (collapsing state) distribution. As the relative size of the bubble increases, the weight of the high variance distribution increases and thus both tails increase at the same time.

Based on the conditional probabilities of a crash and of a rally from both the augmented model and the vNS model, we form a market-timing rule that can be used by the investor to determine when to be in or out of the market. The trading rule states that when the probability of a crash (rally) crosses the upper $90 \%$ percentile $^{21}$ of its historical values, the investor should sell (buy) the index, investing entire wealth in a risk free asset (equities) ${ }^{22}$, and maintain this position until the probability of a crash (rally) becomes lower than its historical

\footnotetext{
${ }^{20}$ The 20 largest consecutive market advances ('draw-ups') are defined as the 20 largest consecutive positive returns, calculated as the return from the last local minimum to the next local maximum.

${ }^{21}$ Focusing on the $90^{\text {th }}$ percentile is somewhat arbitrary, but represents a trade-off between using too high a cut-off which will encourage the investor to remain in the market when the bubble has a historically high probability of collapse, while using too low a cut-off will lead the investor out of the market too frequently, resulting in missed bull market opportunities. Our results are not qualitatively altered if an $85 \%$ or $95 \%$ cut-off is employed instead although for the $95 \%$ cut-off the results are inferior since the investor stays in the market too long.

${ }^{22}$ The risk free rate for the period January 1946 to January 2003 is taken to be the monthly continuously compounded yield on 3-Month Treasury Bills. The data are taken from the Federal Reserve Bank of St Louis web site http://www.stls.frb.org/fred/data/irates.html.
} 
median value, i.e. until the bubble deflates ${ }^{23}$. When the appropriate probability becomes lower than its historical median value, entire wealth should be invested in the S\&P 500 Index. We include the probability of a rally in the strategy since an investor should buy if there is a negative bubble and the probability of a rally is greater than the $90 \%$ percentile of its historical values. In order to ensure that we are not using any information that is not available to the investor in real time, we estimate the probabilities of a crash and of a rally for every rolling sample based on the coefficient estimates of the rolling regression and then calculate the median value and the top $90^{\text {th }} \%$ value recursively with a fixed starting point in January 1888.

We compare the two models by calculating the total holding period return for every month and examine the mean, standard deviation, skewness and kurtosis of each trading rule's return distribution. We note the number of trades that the trading rule has generated over the trading period in order to adjust trading profits for transaction costs, and we also note the percentage of time that an investor following the rule would have invested in equities. To take into account transaction costs, we assume a $0.5 \%$ round trip cost paid upon exit from the market. We then compare the trading performance of the augmented model with the results of the vNS model and with the results of a simple buy and hold strategy.

Furthermore, in order to examine the statistical significance of the profits generated from the trading rule, we form 10,000 long random trading rules created by randomly generating series of zeros and ones, the length of which is equal to the number of months in our trading sample

\footnotetext{
${ }^{23}$ We use the median in order to avoid any unwanted influence from extraordinarily large probabilities of a crash and of a rally observed during the sample period (especially 1929-1933). If we do not use a lower threshold that forces the investor to wait before the bubble deflates, then the results are significantly affected since the investor re-enters the market too early.
} 
(January 1946-January 2003, or 685 months) using a binomial distribution. The probability of success (i.e. of a binomial draw of one) is set equal to the percentage of time that trading rule would suggest the investor to be in the market. We use this probability of success because it yields random trading rules with comparable average holding periods to our trading rules. To test for the statistical significance of the bubble rules we compare the risk adjusted returns and the other moments of the returns' distributions with those of the random rules and if our model yields a risk adjusted profit larger than $90 \%, 95 \%$ or $99 \%$ of the random trading rules, we can conclude that our abnormal profits are statistically significant at the $10 \%, 5 \%$ or $1 \%$ levels respectively. Since this is done to compare the trading rule results to the results of other trading rules that would lead the investor in the market the same percentage of time, we only compare the results prior to adjusting for transaction costs. Finally, for every trading rule generated from the bubble models and the random rules, we calculate the wealth that an investor would have accumulated in January 2003 from an initial investment of one dollar in January 1948.

The results of the augmented model and the vNS model trading rules are presented in Table 3 alongside the results of the buy and hold strategy. The figures in parentheses show the percentage of randomly generated rules that would have led to higher average returns, lower standard deviation, higher skewness etc. Thus, in each case, the lower the percentage value in parentheses, the better the relative performance of the bubble trading model would have been. The second column of Table 3 contains the average of the real total monthly returns of the speculative bubble models' trading rules and the third column the standard deviations of the total returns. Overall, we note that the augmented model trading rule achieves a higher Sharpe ratio since it yields higher average returns than the vNS model with lower standard deviations. For example, using the dividend multiple measure of fundamental values, an 
investor would have received an average return of $0.51 \%$ per month $(6.26 \%$ continuously compounded annualised return) with a standard deviation of $2.09 \%$ if he was using the augmented model compared with $0.36 \%$ (4.39\% annualised) if he was using the vNS model (standard deviation 1.78\%). The difference in average returns decreases if the investor was using the Campbell and Shiller model to estimate fundamental values although the augmented model still yields superior results.

Furthermore, the average return of the augmented model trading rule is statistically significant, since it is greater than the mean return of $99.99 \%$ of the random trading rules, while the vNS model manages to beat $99.90 \%$ of the randomly generated trading rules. The superiority of our model persists if we examine the reward to variability ratio, since the Sharpe ratio for our model is higher than the vNS model's ratio and higher than the Sharpe ratio of $99.99 \%$ of the random trading strategies with the same percentage of time in the market. Moreover, the Sharpe ratio of the augmented model trading rule is higher than the Sharpe ratio of the buy and hold strategy, and this superiority does not fade if we examine the Sharpe ratio after we take into account the transaction costs involved. For both measures of fundamental values, the augmented model trading rule yields significantly higher end of period wealth than the vNS model. This higher end of period wealth is achieved with higher skewness and lower kurtosis coefficients. Both of these higher moments of the distribution of augmented model returns would be more desirable to investors than those of the vNS model under some fairly weak assumptions concerning the shape of investor utility functions (see Scott and Horvath (1980) for higher moment preferences and Kraus \& Litzenberer (1976) and references therein for skewness preference in asset pricing). For example, the augmented model with the dividend multiple measure of fundamental values yields $55 \%$ higher end of period wealth than the vNS model (\$24.79 against $\$ 9.70)$, with a higher Sharpe ratio $(0.21$ 
compared with 0.17), positive skewness and lower kurtosis, with a similar number of trades at 28 (versus 22). Again, the augmented model's end of period wealth and Sharpe ratio are statistically significant since they are higher than the end of period wealth of $99.90 \%$ and the Sharpe ratio of $99.99 \%$ the random trading rules.

The skewness of the distribution of total returns of the augmented model is significantly higher than the skewness of the returns to the buy and hold strategy, although the kurtosis coefficients of the speculative bubble model trading rules' returns are also higher. However, the end of period wealth of the buy and hold strategy is considerably higher than the portfolio value of the augmented model trading rule (\$38.36 compared with $\$ 24.79$ and $\$ 15.40)$. This implies that if an investor used the augmented model to time entry to and exit from the market, he would have less wealth by January 2003 than if he had just held a portfolio of stocks that tracked the index. In order to test whether the augmented speculative behaviour model leads to a higher Sharpe ratio because it causes the investor to be out of the market during volatile periods, we compare our trading results to the results of an error contamination model suggested by van Norden and Vigfusson (1998). This model imposes the restriction that the level of returns across the two regimes is the same, although the variances are not, and that the probability of switching regimes is constant. If this model yields comparable results to the augmented and the vNS models then this would be evidence that there is no non-linear predictability of returns. The error contamination model trading rule results are collected by imposing the following restrictions on the augmented model and then following the rolling regression procedure described above:

$$
\begin{aligned}
& \beta_{C, 0}=\beta_{S, 0} \\
& \beta_{C, b}=\beta_{S, b} \\
& \beta_{S, V}=\beta_{q, b}=\gamma_{q, V}=0
\end{aligned}
$$


$\sigma_{S} \neq \sigma_{C}$

From the results of the error contamination model trading rule presented in Table 2 ("EC model" in the table), we can see that the results of the augmented and the vNS trading rules demonstrate some non-linear predictability of returns that is captured by the speculative behavior models. The error contamination model leads to significantly lower end-of-period wealth and Sharpe ratios than both the augmented and vNS models. In order to further ensure that the results are not just attributable to the avoidance of high volatility periods, we allow for the probability of being in the surviving regime to be a function of bubble size and abnormal volume and we re-estimate the error contamination model by imposing only the following restrictions and repeating the procedure described above:

$$
\begin{aligned}
& \beta_{C, 0}=\beta_{S, 0} \\
& \beta_{C, b}=\beta_{S, b} \\
& \beta_{S, V}=0 \\
& \sigma_{S} \neq \sigma_{C}
\end{aligned}
$$

The results for this model are again inferior to the augmented model implying that our model is timing the market more efficiently by capturing some nonlinear predictability of returns.

Examining the augmented model trading rule in more detail, shows that the lower end of period wealth relative to the buy and hold strategy is caused by the large bubble deviation that is observed towards the end of the sample. Although this large and persistent bubble significantly decreases in value in the last three years of the sample, it does not fully collapse in our sample and thus it causes the speculative bubble model to produce a large probability of a crash throughout the 1990's and at the end of the sample period. Figures 7 and 8 plot the real S\&P 500 Composite Index together with the net excess wealth of the augmented model 
trading rule and of the vNS model trading rule respectively as a percentage of the wealth of the buy and hold strategy. On the plots of the S\&P 500, we place markers that signify entry and exit times that the trading rules have generated using the dividend multiple measure of fundamentals. In these figures, investor wealth has been adjusted for transaction costs assuming a $0.5 \%$ round trip cost paid upon exit from the market.

From Figure 7, it is evident that the augmented model, estimated using the dividend multiple measure of fundamentals, forces the investor to be out of the market for long periods of time (especially in the 1960's and 1990's). Nevertheless, it produces higher wealth than the buy and hold strategy until December 1992. At the end of the sample, however, the buy and hold strategy yields significantly higher wealth since the large observed bubble deviation does not fully reverse during the sample period employed. Furthermore, the augmented model underperforms the buy and hold strategy in the 1960's, since the fundamental values produce a large and persistent bubble that collapses in 1970. This causes the augmented model to produce large probabilities of extreme returns and thus the trading rule produces a sell signal for long periods of time, leading the investor to be out of the market $61.75 \%$ of the time.

Examining the trading rule results of the augmented model using the Campbell and Shiller fundamental values, we note that the augmented model trading rule produces a persistent sell signal for shorter periods of time (see Figure 9$)^{24}$. However, the augmented model trading rule yields a lower wealth than the buy and hold strategy for the entire sample. This is mainly due to the late entry of the investor in the market in the beginning of the 1950's when the market experienced significant positive returns. The fact that the speculative behavior models 
cannot yield higher absolute wealth than the buy and hold strategy can be attributed to a number of possible reasons. First, it is possible that a bubble of the form assumed was not present in the data at the end of the sample period or it is possible that the model used to estimate fundamental values is not adequate and does not capture fundamentals precisely. An alternative explanation is that this result is the consequence of a manifestation of the "peso problem",25, where the speculative bubble models suggest that a market crash is imminent, but do not suggest a precise date when this will occur. Such an event did not occur during the sample period, but this does not mean that it was wrong to predict that it would; indeed, the market was subject to substantial falls in the end of the sample but both measures of fundamentals yield a significant positive bubble deviation in January 2003.

Finally, it should be noted that while the augmented vNS model cannot improve upon a buyand-hold rule in pure return terms, it does lead to a higher Sharpe ratio and is useful for investors as a way to reduce the risk of holding equity portfolios.

\section{CONCLUSIONS}

Although van Norden and Vigfusson (1998) examine the statistical power and reliability of regime switching bubble models, to our knowledge no existing research has examined the financial usefulness of models of speculative bubbles. We test the out-of-sample forecasting ability of the regime switching model of van Norden and Schaller and of an augmented version of it in a financially intuitive way. We construct trading rules based on inferences about the conditional probability of a crash and of a rally, and analyse the risk-adjusted

\footnotetext{
${ }^{24}$ For comparison, we plot the net excess wealth generated from the vNS model trading rule using the Campbell and Shiller (1987) measure of fundamentals in Figure 10.

${ }^{25}$ See Evans (1996) for a thorough description of the impact of peso problems for asset pricing models.
} 
returns obtained with the use of the vNS model and the augmented model. In order to ensure that we have not used any data that would not have been available to investors, we estimate the vNS and augmented model using rolling regressions with a fixed starting point. We examine the timing ability of the bubble models by comparing the returns of the speculative bubble model trading rules with the returns on 10,000 randomly generated trading rules that have the same average proportion of the sample period invested in equities. We find that the augmented model can consistently lead to higher risk adjusted returns than the vNS model and the randomly generated trading rules, although it does not beat the buy and hold strategy in risk-unadjusted (total end of period wealth) terms.

This result is mainly attributed to the fact that the estimated fundamental values yield a significant and persistent positive bubble deviation in the 1990's, thus causing the augmented model to produce large conditional probabilities of a crash. Therefore, the augmented model trading rule forced the investor to remain out of the market for protracted periods of time, while a full correction did not occur by the end of our sample period. An alternative approach would be to allow the observed bubble deviations to follow a different generating process than the one described by Blanchard and Watson (1982) and used by vNS. More specifically, it could be the case that bubble deviations are systematic and persistent during long periods of time before entering a 'critical' state in which the probability of collapse is significantly higher. A bubble process that could produce such 'distinct' periods of deterministic and explosive growth has been described in Evans (1991), and the investigation of the empirical usefulness of such speculative bubble models appears to be a fruitful avenue for further research $^{26}$.

\footnotetext{
${ }^{26}$ See Brooks and Katsaris (2004) for one possible such model.
} 


\section{REFERENCES}

Billio, Monica, and Loriana Pelizzon. 2000. Value at Risk: A Multivariate Regime Switching Approach. Journal of Empirical Finance 7 (December): 531-554.

Blanchard, Oliver J., and Mark W. Watson. 1982. Bubbles, Rational Expectations and Financial Markets. NBER Working Paper no. 945, Cambridge, Mass.: National Bureau of Economic Research.

Brooks, Chris, and Apostolos Katsaris. 2002. Regime Switching Models of Speculative Bubbles with Volume: An Empirical Investigation of the S\&P500 Composite Index. Unpublished manuscript, ISMA Centre, University of Reading.

-----. 2004. A Three-Regime Model of Speculative Behaviour: Modelling the Evolution of Bubbles in the S\&P 500 Composite Index. Economic Journal (in press)

Campbell, John Y., and Robert Shiller. 1987. Cointegration and Tests of Present Value Models. Journal of Political Economy 95 (October): 1062-1088.

Cutler, David M., James M. Poterba, and Lawrence H. Summers. 1991. Speculative Dynamics. Review of Economic Studies 58 (May): 529-546.

Diba, Behzad T., and Herschel I. Grossman. 1988. Explosive Rational Bubbles in Stock Prices? American Economic Review 78 (June): 520-530.

Evans, George W. 1991. Pitfalls in Testing for Explosive Bubbles in Asset Prices. American Economic Review 81 (September): 922-930.

Evans, Martin D. 1996. Peso Problems: Their Theoretical and Empirical Implications. In Handbook of Statistics: Vol. 14, eds. Maddala G. S., and Calyampudi R. Rao. Amsterdam: Elsevier. 
Flood, Robert P., and Peter Garber. 1980. Market Fundamentals Versus Price Level Bubbles: The first Tests. Journal of Political Economy 88 (August): 745-770.

Flood, R Robert P., Peter Garber, and Louis Scott 1984. Multi Country Tests for Price Level Bubbles. Journal of Economic Dynamics and Control 8 no. 2: 329-340.

Hall, Stephen G.; Zacharias Psaradakis, and Martin Sola. 1999. Detecting Periodically Collapsing Bubbles: A Markov-Switching Unit Root Test. Journal of Applied Econometrics 14 (March/April): 143-154.

Kindleberger, Charles P. 1989. Manias, Panics and Crashes: A History of Financial Crises. Macmillan, London.

Kraus, Alan, and Robert H. Litzenberger. 1976. Skewness Preference and the Valuation of Risky Assets. Journal of Finance 31 (September): 1085-1100.

Maheu, John M., and Thomas H. McCurdy. 2000. Identifying Bull and Bear Markets in Stock Returns. Journal of Business and Economic Statistics 18: 100-112.

McQueen, Grant, and Steven Thorley. 1994. Bubbles, Stock Returns, and Duration Dependence. Journal of Financial and Quantitative Analysis 29 (September): 379-401.

Salge, Matthias. 1997. Rational Bubbles: Theoretical Basis, Economic Relevance and Empirical Evidence with a Special Emphasis on the German Stock Market. Berlin: Springer.

Scott, Robert, and Phillip Horvath. 1980. On the Direction of Preference for Moments of Higher Order than the Variance. Journal of Finance 35 (September): 915-919.

Shiller, Robert J. 1981. Do Stock Prices Move Too Much to be Justified by Subsequent Changes in Dividends. American Economic Review 71 (May): 421-36.

------. 2000. Irrational Exuberance. Princeton, New Jersey: Princeton University Press. 
Summers, Lawrence H. 1986. Does the Stock Market Rationally Reflect Fundamental Values? Journal of Finance 41 (July): 591-603.

van Norden, Simon. 1996. Regime Switching as a Test for Exchange Rate Bubbles. Journal of Applied Econometrics 11 (May-June): 219-51.

van Norden, Simon, and Huntley Schaller. 1993. The Predictability of Stock Market Regime: Evidence from the Toronto Stock Exchange. Review of Economics and Statistics 75 (August): 505-510.

------. 1997. Fads or Bubbles? Bank of Canada Working Paper no. 97-2.

-----. 1999. Speculative Behavior, Regime-Switching, and Stock Market Crashes. In Nonlinear Time Series Analysis of Economic and Financial Data, ed. Philip Rothman: 321356.

van Norden Simon, and Robert Vigfusson. 1998. Avoiding the Pitfalls: Can Regime Switching Tests Reliably Detect Bubbles? Studies in Nonlinear Dynamics and Econometrics 3 (April): 1-22.

West, Kenneth D. 1987. A specification Test for Speculative Bubbles. Quarterly Journal of Economics 102 (August): 553-580.

\section{APPENDIX: CALCULATION OF FUNDAMENTAL VALUES}

In order to construct fundamental values, we examine two different specifications that use only information on past prices and dividends. The models used are the dividend multiple model of van Norden and Schaller (1999), and a mathematical manipulation of Campbell and Shiller's (1987) VAR model of dividend components of prices. The dividend multiple model of fundamental values assumes a constant dividend-price ratio whereas the Campbell and 
Shiller measure allows for predictable variation in the dividend growth rate. Both models assume constant discount rates.

\section{DIVIDEND MULTIPLE MEASURE OF FUNDAMENTALS}

vNS show that if the discount rate is constant, then stock market prices follow the period-byperiod arbitrage condition:

$$
p_{t}=\frac{E_{t}\left(p_{t+1}+d_{t+1}\right)}{(1+i)}
$$

Assuming that dividends follow a geometric random walk, i.e. that log dividends follow a random walk with a drift, it can be shown that the fundamental price of a stock will be equal to a multiple of current dividends:

$$
p_{t}^{f}=\rho d_{t}
$$

where: $\rho=\frac{1+r}{e^{\left(a+\frac{\sigma^{2}}{2}\right)}-1}$

We use the sample mean of the price-dividend ratio to approximate $\rho$. In this setting, the relative bubble size is given by:

$$
B_{t}=\frac{b_{t}}{p_{t}}=\frac{p_{t}-p_{t}^{f}}{p_{t}}=1-\frac{\rho d_{t}}{p_{t}}
$$

\section{CAMPBELL AND SHILLER FUNDAMENTAL VALUES}

The dividend multiple measure of fundamental values assumes that the expected dividend growth rate is constant. In order to allow for predictable variation in the dividend growth rate, we estimate fundamental values based on the Campbell and Shiller (1987) dividend component of prices. It can be shown that the spread between stock prices and a constant 
multiple of current dividends is the optimal forecast of a multiple of the discounted value of all future dividend changes:

$S_{t} \equiv p_{t}^{f}-\frac{1+i}{i} d_{t}=\frac{1+i}{i}\left(\sum_{g=1}^{\infty} \frac{1}{(1+i)^{g}} E_{t}\left(\Delta d_{t+g}\right)\right)$

Using the VAR methodology developed by Campbell and Shiller, we examine whether changes in dividends can be forecasted by the spread between prices and the multiple of current dividends. If the changes in dividends cannot be forecasted by the spread, this would imply that investors use only past dividends to form expectations about future dividends. If, on the other hand, investors include other variables in their information set then this information will be reflected in past prices and thus past realisations of the spread. This would imply that the spread has power to forecast future dividend changes. We examine this relationship using the following VAR:

$\left[\begin{array}{c}\Delta d_{t} \\ S_{t}\end{array}\right]=\left[\begin{array}{ll}a(L) & b(L) \\ c(L) & d(L)\end{array}\right]\left[\begin{array}{c}\Delta d_{t-1} \\ S_{t-1}\end{array}\right]+\left[\begin{array}{l}u_{1 t} \\ u_{2 t}\end{array}\right]$

where: both $\Delta d_{t}$ and $S_{t}$ are de-meaned. This matrix equation can be rewritten more compactly as:

$z_{t}=A z_{t-1}+v_{t}$

This VAR can be used to forecast future dividend changes conditional on the information set $\left(H_{t}\right)$ described above that contains data on past dividend growth rates and realisations of the spread. The present value of future dividend changes, equal to the fundamental spread, can be forecasted from equation (A6) using the following equation:

$$
S_{t}^{*}=E_{t}\left(S_{t}^{f} \mid H_{t-1}\right)=\left(\frac{1+i}{i}\right) \omega^{\prime}\left(\frac{1}{1+i}\right) A\left(I-\left(\frac{1}{1+i}\right) A\right)^{-1} z_{t}
$$


where $\omega$ is a row vector that picks out $\Delta d_{t-1}{ }^{27}$. The fundamental price can thus be calculated by solving equation (A7):

$p_{t}^{f}=S_{t}^{*}+\left(\frac{1+i}{i}\right) d_{t-1}$

where $i$ is the average real total return over the entire period. We construct fundamental values using equation (A8). The second measure of relative bubble size is thus given by:

$B_{t}=1-\frac{S_{t}^{*}+\left(\frac{1+i}{i}\right) d_{t-1}}{p_{t}}$

\footnotetext{
${ }^{27}$ See Campbell and Shiller (1987) for more details concerning the methodology.
} 
Table 1:

Results of the Periodically Collapsing Speculative Bubble Models for the Dividend Multiple Measure of Fundamental Values. January 1888 - January 2003.

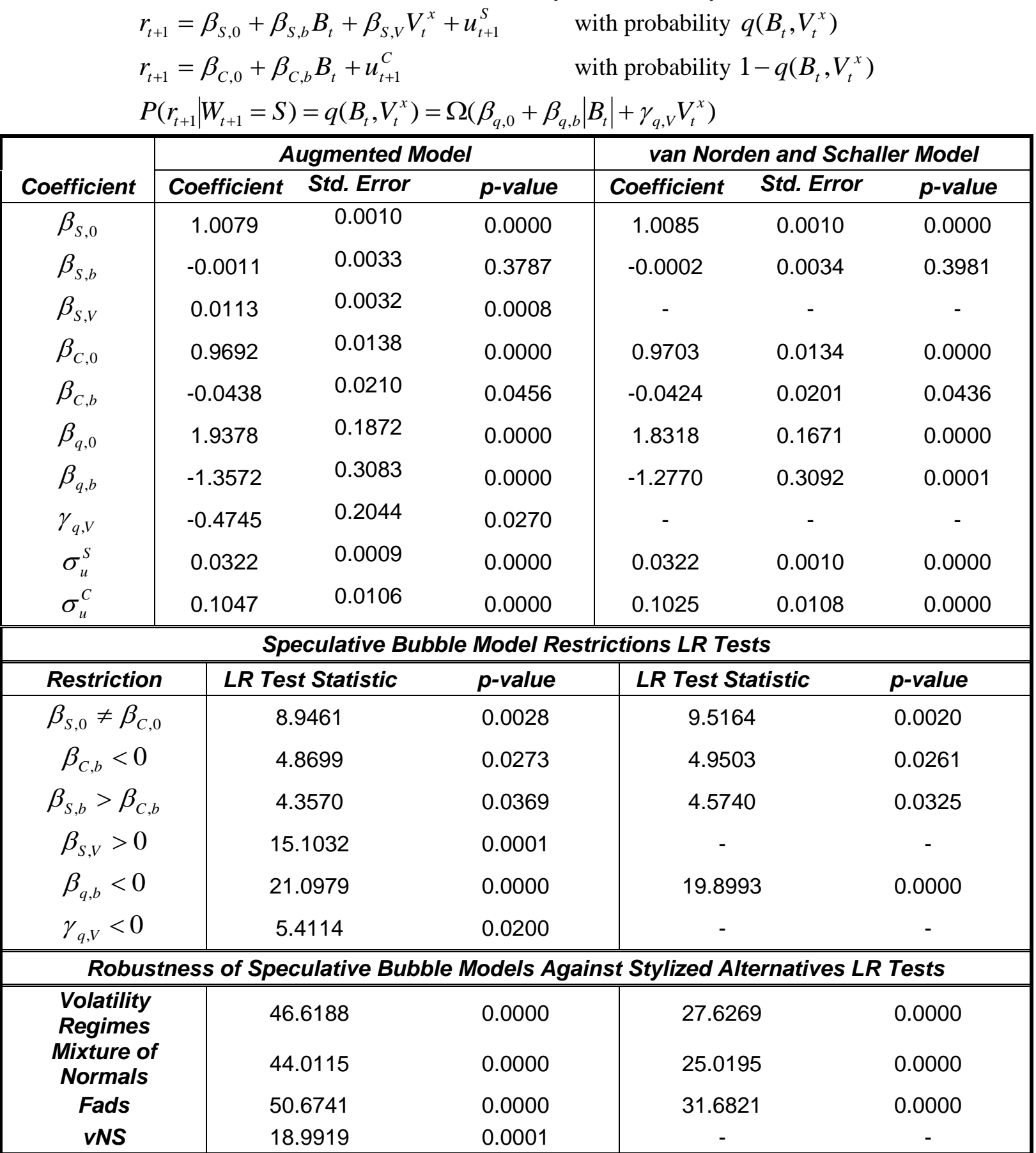

The van Norden and Schaller model coefficients are estimated using the model described in equation (13) in the text. The $p$-values are calculated using standard errors estimated from the inverse of the Hessian matrix at the optimum. The volatility regimes test imposes the restrictions: $\beta_{S, 0}=\beta_{C, 0}$ and $\beta_{S, b}=\beta_{C, b}=\beta_{q, b}=\beta_{S, V}=\gamma_{q, b}=0$. The mixture of normals test imposes the restrictions $\beta_{S, b}=\beta_{C, b}=\beta_{q, b}=\beta_{S, V}=\gamma_{q, b}=0$. The fads test imposes the restrictions $\beta_{S, 0}=\beta_{C, 0}, \beta_{S, b}=\beta_{C, b}$ and $\beta_{q, b}=\beta_{S, V}=\gamma_{q, b}=0$. The vNS test imposes the restrictions $\beta_{S, v}=\gamma_{q, b}=0$. 
Table 2:

Results of the Periodically Collapsing Speculative Bubble Models for the Campbell and Shiller Measure of Fundamental Values. January 1888 - January 2003.

$$
\begin{array}{ll}
r_{t+1}=\beta_{S, 0}+\beta_{S, b} B_{t}+\beta_{S, V} V_{t}^{x}+u_{t+1}^{S} & \text { with probability } q\left(B_{t}, V_{t}^{x}\right) \\
r_{t+1}=\beta_{C, 0}+\beta_{C, b} B_{t}+u_{t+1}^{C} & \text { with probability } 1-q\left(B_{t}, V_{t}^{x}\right) \\
P\left(r_{t+1} \mid W_{t+1}=S\right)=q\left(B_{t}, V_{t}^{x}\right)=\Omega\left(\beta_{q, 0}+\beta_{q, b}\left|B_{t}\right|+\gamma_{q, V} V_{t}^{x}\right) &
\end{array}
$$

\begin{tabular}{|c|c|c|c|c|c|c|}
\hline \multirow[b]{2}{*}{ Coefficient } & \multicolumn{3}{|c|}{ Augmented Model } & \multicolumn{3}{|c|}{ van Norden and Schaller Model } \\
\hline & Coefficient & Std. Error & $p$-value & Coefficient & Std. Error & $p$-value \\
\hline$\beta_{S, 0}$ & 1.0079 & 0.0010 & 0.0000 & 1.0084 & 0.0011 & 0.0000 \\
\hline$\beta_{S, b}$ & -0.0005 & 0.0036 & 0.3951 & 0.0004 & 0.0036 & 0.3963 \\
\hline$\beta_{S, V}$ & 0.0113 & 0.0032 & 0.0010 & - & - & - \\
\hline$\beta_{C, 0}$ & 0.9645 & 0.0152 & 0.0000 & 0.9656 & 0.0154 & 0.0000 \\
\hline$\beta_{C, b}$ & -0.0421 & 0.0196 & 0.0393 & -0.0411 & 0.0198 & 0.0467 \\
\hline$\beta_{q, 0}$ & 1.9323 & 0.1763 & 0.0000 & 1.8538 & 0.1729 & 0.0000 \\
\hline$\beta_{q, b}$ & -1.3723 & 0.2888 & 0.0000 & -1.3430 & 0.2959 & 0.0000 \\
\hline$\gamma_{q, V}$ & -0.4427 & 0.2031 & 0.0372 & - & - & - \\
\hline$\sigma_{u}^{s}$ & 0.0323 & 0.0009 & 0.0000 & 0.0324 & 0.0010 & 0.0000 \\
\hline$\sigma_{u}^{C}$ & 0.1064 & 0.0108 & 0.0000 & 0.1046 & 0.0112 & 0.0000 \\
\hline \multicolumn{7}{|c|}{ Speculative Bubble Model Restrictions LR Tests } \\
\hline \multicolumn{3}{|c|}{ Restriction } & $\begin{array}{l}\text { LR Test } \\
\text { Statistic }\end{array}$ & $p$-value & $\begin{array}{l}\text { LR Test } \\
\text { Statistic }\end{array}$ & $p$-value \\
\hline \multicolumn{2}{|c|}{$\beta_{S, 0} \neq \beta_{C, 0}$} & & 9.3987 & 0.0022 & 9.8948 & 0.0017 \\
\hline \multicolumn{2}{|c|}{$\beta_{C, b}<0$} & & 4.9973 & 0.0254 & 5.1197 & 0.0237 \\
\hline \multicolumn{2}{|c|}{$\beta_{S, b}>\beta_{C, b}$} & & 4.5657 & 0.0326 & 4.8548 & 0.0276 \\
\hline \multicolumn{2}{|c|}{$\beta_{S, V}>0$} & & 14.6175 & 0.0001 & - & - \\
\hline \multicolumn{2}{|c|}{$\beta_{q, b}<0$} & & 27.6874 & 0.0000 & 27.4445 & 0.0000 \\
\hline \multicolumn{2}{|c|}{$\gamma_{q, V}<0$} & & 4.8905 & 0.0270 & - & - \\
\hline \multicolumn{7}{|c|}{ Robustness of Speculative Bubble Models Against Stylized Alternatives LR Tests } \\
\hline \multicolumn{3}{|c|}{\begin{tabular}{l|l} 
Volatility Regimes &
\end{tabular}} & 52.3807 & 0.0000 & 33.9732 & 0.0000 \\
\hline \multicolumn{3}{|c|}{ Mixture of Normals } & 49.9112 & 0.0000 & 31.5038 & 0.0000 \\
\hline \multicolumn{3}{|c|}{ Fads } & 57.1273 & 0.0000 & 38.7199 & 0.0000 \\
\hline \multicolumn{3}{|c|}{$v N S$} & 18.4074 & 0.0001 & - & - \\
\hline
\end{tabular}

The van Norden and Schaller model coefficients are estimated using the model described in equation (13) in the text. The $p$-values are calculated using standard errors estimated from the inverse of the Hessian matrix at the optimum. The volatility regimes test imposes the restrictions: $\beta_{S, 0}=\beta_{C, 0}$ and $\beta_{S, b}=\beta_{C, b}=\beta_{q, b}=\beta_{S, V}=\gamma_{q, b}=0$. The mixture of normals test imposes the restrictions $\beta_{S, b}=\beta_{C, b}=\beta_{q, b}=\beta_{S, V}=\gamma_{q, b}=0$. The fads test imposes the restrictions $\beta_{S, 0}=\beta_{C, 0}, \beta_{S, b}=\beta_{C, b}$ and $\beta_{q, b}=\beta_{S, V}=\gamma_{q, b}=0$. The vNS test imposes the restrictions $\beta_{S, V}=\gamma_{q, b}=0$. 


\section{Figure 1:}

Bubble Deviation of Actual Price from Fundamental Values.

January 1888 - January 2003.

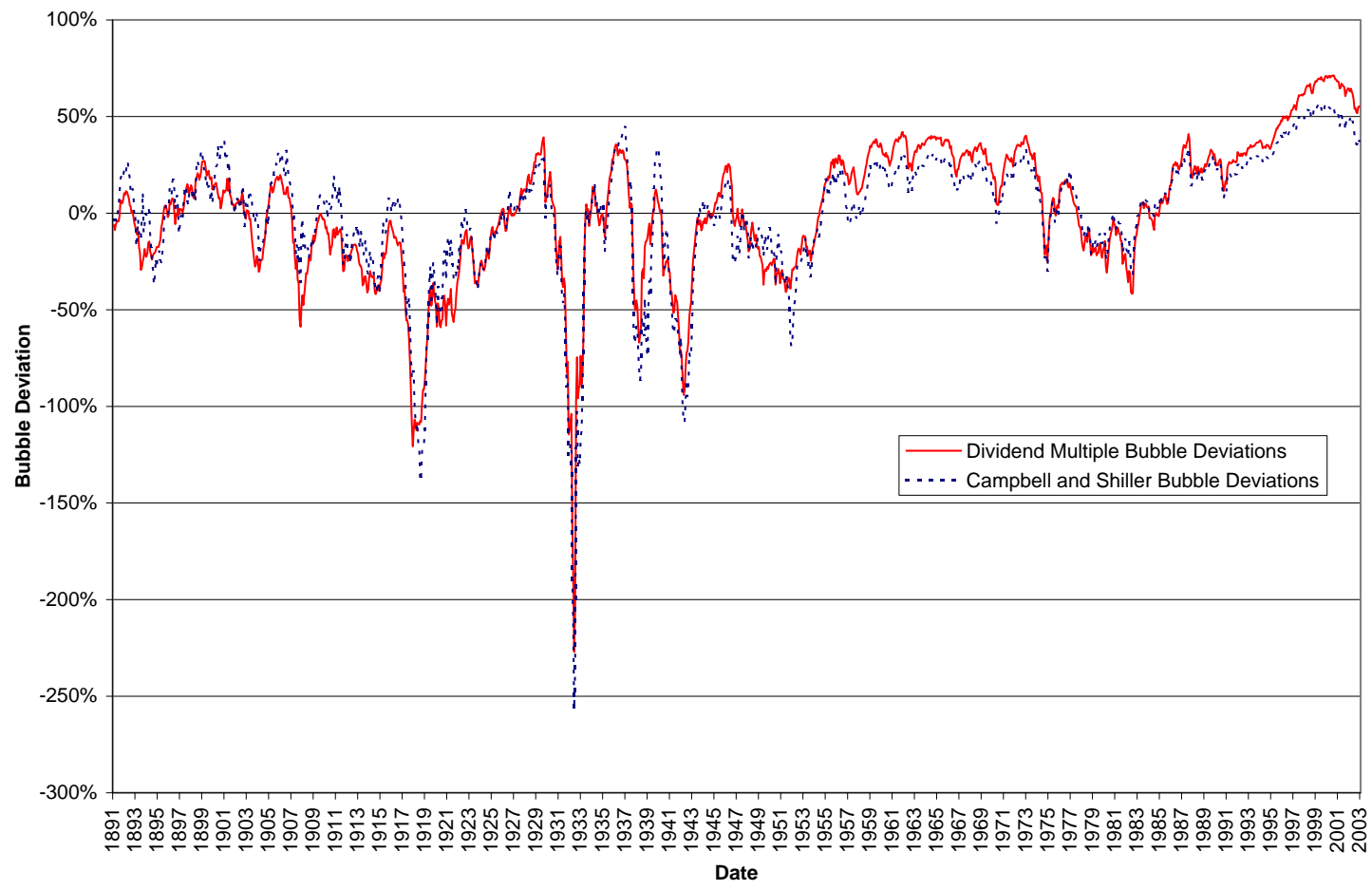

Figure 2:

Probability of being in the Surviving Regime in $t+1$ : Dividend Multiple Measure of Bubble Deviations. January 1888 - January 2003.

The probability of collapse is given by: $1-P\left(W_{t+1}=S\right)=1-\Omega\left(\beta_{q, 0}+\beta_{q, b}\left|B_{t}\right|+\gamma_{q, V} V_{t}^{x}\right)$

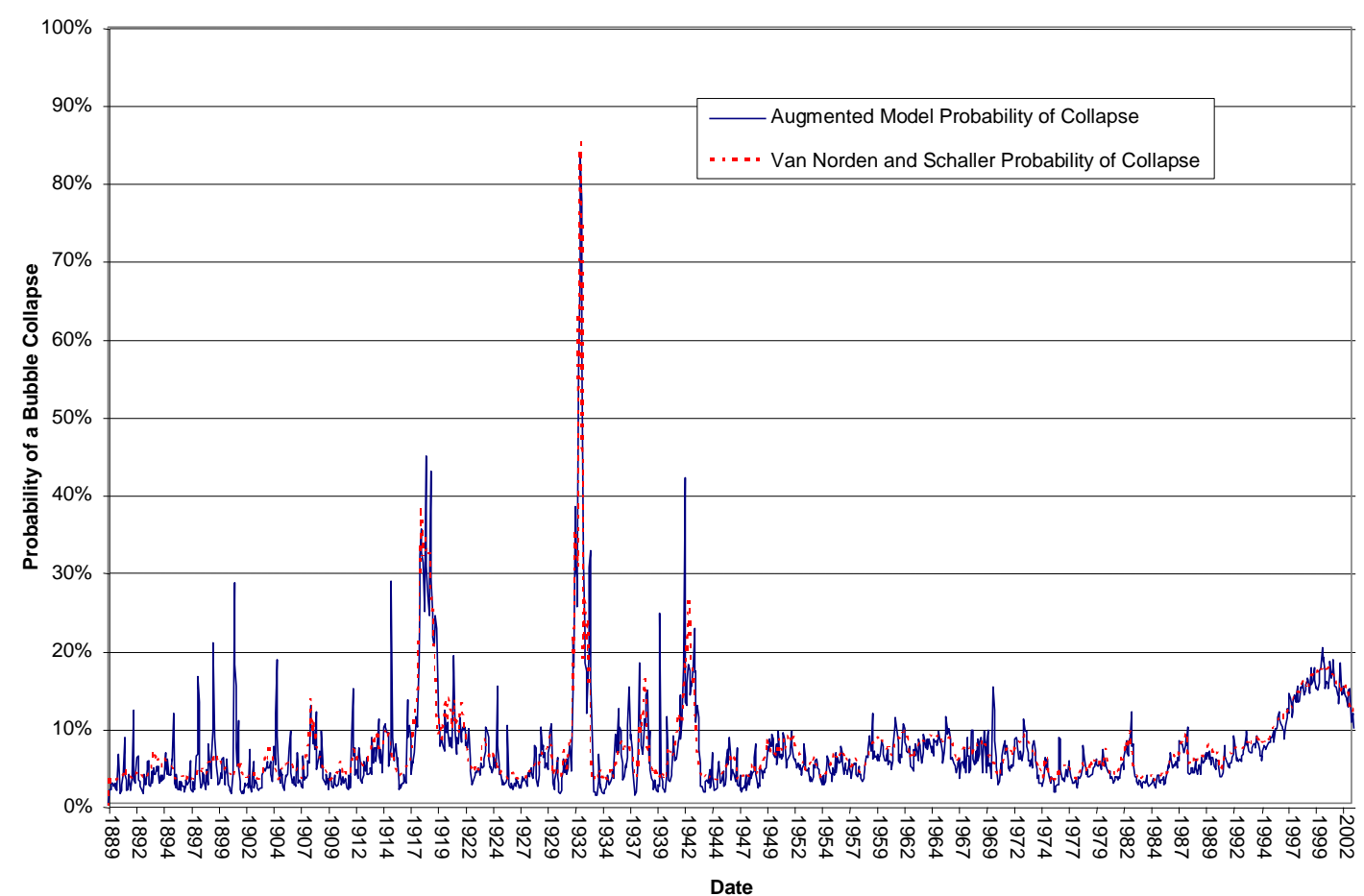


Table 3: Speculative Bubble Models' Trading Rules Results against Randomly Generated Trading Rules and the Buy and Hold Strategy,

January 1946 - January 2003

\begin{tabular}{|c|c|c|c|c|c|c|c|c|c|c|}
\hline Strategy & $\begin{array}{l}\text { Mean } \\
\text { Return }\end{array}$ & $\begin{array}{l}\text { Standard } \\
\text { Deviation }\end{array}$ & Skewness & $\begin{array}{l}\text { Excess } \\
\text { Kurtosis }\end{array}$ & $\begin{array}{l}\text { End of } \\
\text { Period } \\
\text { Wealth }\end{array}$ & $\begin{array}{c}\text { Sharpe } \\
\text { Ratio }\end{array}$ & $\begin{array}{c}\% \text { of Time } \\
\text { in the } \\
\text { Market }\end{array}$ & $\begin{array}{c}\text { Number of } \\
\text { (round trip) } \\
\text { Trades }\end{array}$ & $\begin{array}{c}\text { Adjusted } \\
\text { Sharpe } \\
\text { Ratio } \\
\end{array}$ & $\begin{array}{c}\text { Adjusted End } \\
\text { of Period } \\
\text { Wealth }\end{array}$ \\
\hline $\begin{array}{c}\text { Buy and } \\
\text { Hold }\end{array}$ & $0.60 \%$ & $3.52 \%$ & -0.60 & 1.76 & $\$ 38.36$ & 0.1541 & $100.00 \%$ & 1 & 0.1540 & $\$ 38.17$ \\
\hline $\begin{array}{c}\text { Risk Free } \\
\text { Investment }\end{array}$ & $0.05 \%$ & $0.44 \%$ & -1.64 & 6.67 & $\$ 1.44$ & - & $0.00 \%$ & - & - & - \\
\hline \multicolumn{11}{|c|}{ Dividend Multiple Measure of Fundamentals } \\
\hline $\begin{array}{c}\text { Augmented } \\
\text { Model }\end{array}$ & $\begin{array}{c}0.51 \% \\
(0.00 \%)\end{array}$ & $\begin{array}{c}2.09 \% \\
(12.23 \%)\end{array}$ & $\begin{array}{c}0.44 \\
(1.19 \%)\end{array}$ & $\begin{array}{c}5.83 \\
(0.20 \%)\end{array}$ & $\begin{array}{c}\$ 24.79 \\
(0.00 \%)\end{array}$ & $\begin{array}{c}0.2172 \\
(0.00 \%)\end{array}$ & $38.25 \%$ & 14 & 0.2113 & $\$ 23.11$ \\
\hline vNS Model & $\begin{array}{c}0.36 \% \\
(0.10 \%)\end{array}$ & $\begin{array}{c}1.78 \% \\
(42.74 \%)\end{array}$ & $\begin{array}{c}1.37 \\
(0.20 \%)\end{array}$ & $\begin{array}{c}12.57 \\
(9.05 \%)\end{array}$ & $\begin{array}{c}\$ 9.70 \\
(0.20 \%)\end{array}$ & $\begin{array}{c}0.1711 \\
(0.10 \%)\end{array}$ & $24.53 \%$ & 11 & 0.1663 & $\$ 9.18$ \\
\hline $\begin{array}{c}E C B V \\
\text { Model }\end{array}$ & $\begin{array}{c}0.38 \% \\
(45.83 \%) \\
\end{array}$ & $\begin{array}{l}2.51 \% \\
(0.89 \%) \\
\end{array}$ & $\begin{array}{c}-0.50 \\
(44.23 \%) \\
\end{array}$ & $\begin{array}{c}5.04 \\
(0.40 \%) \\
\end{array}$ & $\begin{array}{c}\$ 10.97 \\
(41.85 \%)\end{array}$ & $\begin{array}{c}0.1306 \\
(27.14 \%) \\
\end{array}$ & $58.89 \%$ & 13 & 0.1291 & $\$ 10.28$ \\
\hline EC Model & $\begin{array}{c}0.28 \% \\
(73.26 \%)\end{array}$ & $\begin{array}{c}2.58 \% \\
(75.75 \%)\end{array}$ & $\begin{array}{c}-0.48 \\
(46.72 \%)\end{array}$ & $\begin{array}{c}5.90 \\
(0.60 \%)\end{array}$ & $\begin{array}{c}\$ 5.36 \\
(74.55 \%)\end{array}$ & $\begin{array}{c}0.0869 \\
(75.84 \%)\end{array}$ & $49.27 \%$ & 3 & 0.0807 & $\$ 4.80$ \\
\hline \multicolumn{11}{|c|}{ Campbell and Shiller Measure of Fundamentals } \\
\hline $\begin{array}{c}\text { Augmented } \\
\text { Model }\end{array}$ & $\begin{array}{c}0.43 \% \\
(2.09 \%) \\
\end{array}$ & $\begin{array}{l}2.27 \% \\
(9.05 \%)\end{array}$ & $\begin{array}{c}-0.23 \\
(22.17 \%) \\
\end{array}$ & $\begin{array}{c}7.06 \\
(1.09 \%)\end{array}$ & $\begin{array}{l}\$ 15.40 \\
(3.18 \%)\end{array}$ & $\begin{array}{c}0.1694 \\
(0.99 \%) \\
\end{array}$ & $45.54 \%$ & 15 & 0.1640 & $\$ 14.29$ \\
\hline vNS Model & $\begin{array}{c}0.37 \% \\
(3.98 \%)\end{array}$ & $\begin{array}{c}2.01 \% \\
(4.47 \%)\end{array}$ & $\begin{array}{c}0.19 \\
(4.87 \%)\end{array}$ & $\begin{array}{c}7.49 \\
(1.29 \%)\end{array}$ & $\begin{array}{c}\$ 10.09 \\
(3.28 \%)\end{array}$ & $\begin{array}{c}0.1564 \\
(1.39 \%)\end{array}$ & $36.79 \%$ & 12 & 0.1517 & $\$ 9.50$ \\
\hline $\begin{array}{l}\text { EC B V } \\
\text { Model }\end{array}$ & $\begin{array}{c}0.34 \% \\
(76.74 \%)\end{array}$ & $\begin{array}{l}2.62 \% \\
(4.57 \%)\end{array}$ & $\begin{array}{c}-0.71 \\
(84.10 \%)\end{array}$ & $\begin{array}{c}5.29 \\
(0.40 \%)\end{array}$ & $\begin{array}{c}\$ 8.07 \\
(74.25 \%)\end{array}$ & $\begin{array}{c}0.1089 \\
(67.50 \%)\end{array}$ & $61.37 \%$ & 9 & 0.1084 & $\$ 7.71$ \\
\hline EC Model & $\begin{array}{c}0.32 \% \\
37.67 \%\end{array}$ & $\begin{array}{l}2.35 \% \\
24.25 \%\end{array}$ & $\begin{array}{c}-0.32 \\
27.14 \%\end{array}$ & $\begin{array}{c}6.55 \\
0.70 \%\end{array}$ & $\begin{array}{c}\$ 7.36 \\
36.88 \%\end{array}$ & $\begin{array}{l}0.1129 \\
33.60 \%\end{array}$ & $45.92 \%$ & 6 & 0.1007 & $\$ 6.06$ \\
\hline
\end{tabular}

Trading rules are formed based on the conditional probability of a crash when a positive bubble is present and the conditional probability of a rally when a negative bubble is present. The investor either places his entire wealth in the S\&P 500 Composite Index or in the 3-month U.S. Treasury Bill. The end of period wealth is the real value of the investor's portfolio in January 2003 if the initial value of the portfolio in January 1946 was $\$ 1.00$. All the numbers and the returns are in real terms. Figures in parentheses show the percentile ranking of the trading rule relative to 10,000 random trading rules with an equal percentage of time invested in the index. The mean return is the average monthly real total return and the standard deviation of returns is the standard deviation of total returns. The Sharpe ratio is the ratio of the mean excess return of a given trading rule over the corresponding standard deviation of returns. The percentage of time in the market is the percentage of months the trading rule produced a hold signal out of the 685 months in the sample. The number of trades is the total number of buy and sell orders produced by a given trading rule. The adjusted end of period wealth shows the end of period wealth net of transaction costs. Transaction costs are assumed to be $0.5 \%$ per round trip on the total value of the trade. $E C$ denotes the error contamination model - see text for details. 
Figure 3:

Probabilities of a Crash from the vNS and the Augmented Model. Dividend Multiple Measure of Fundamental Values January 1946 - January 2003

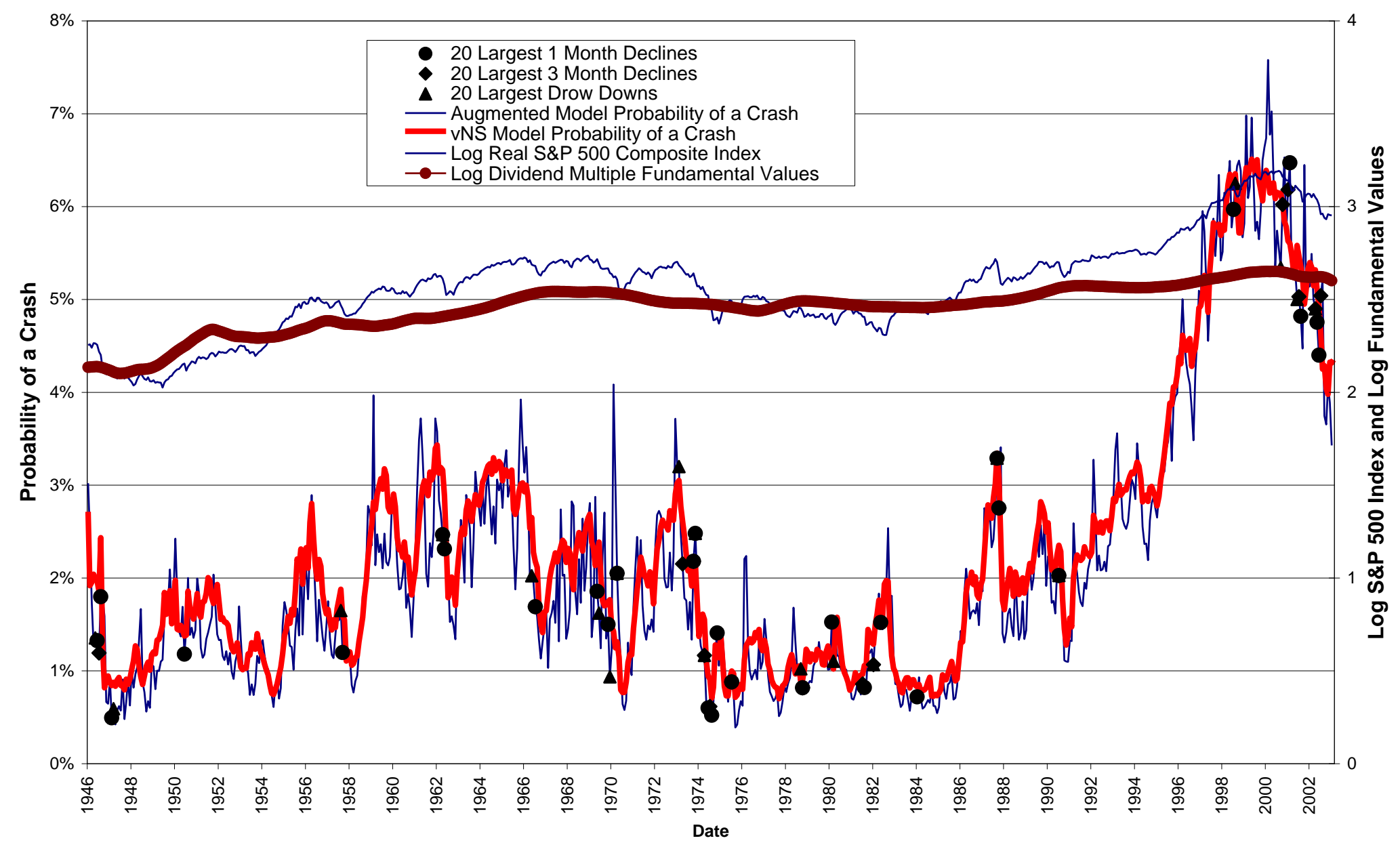


Figure 4:

Probabilities of a Rally from the vNS and the Augmented Model. Dividend Multiple Measure of Fundamental Values January 1946 - January 2003

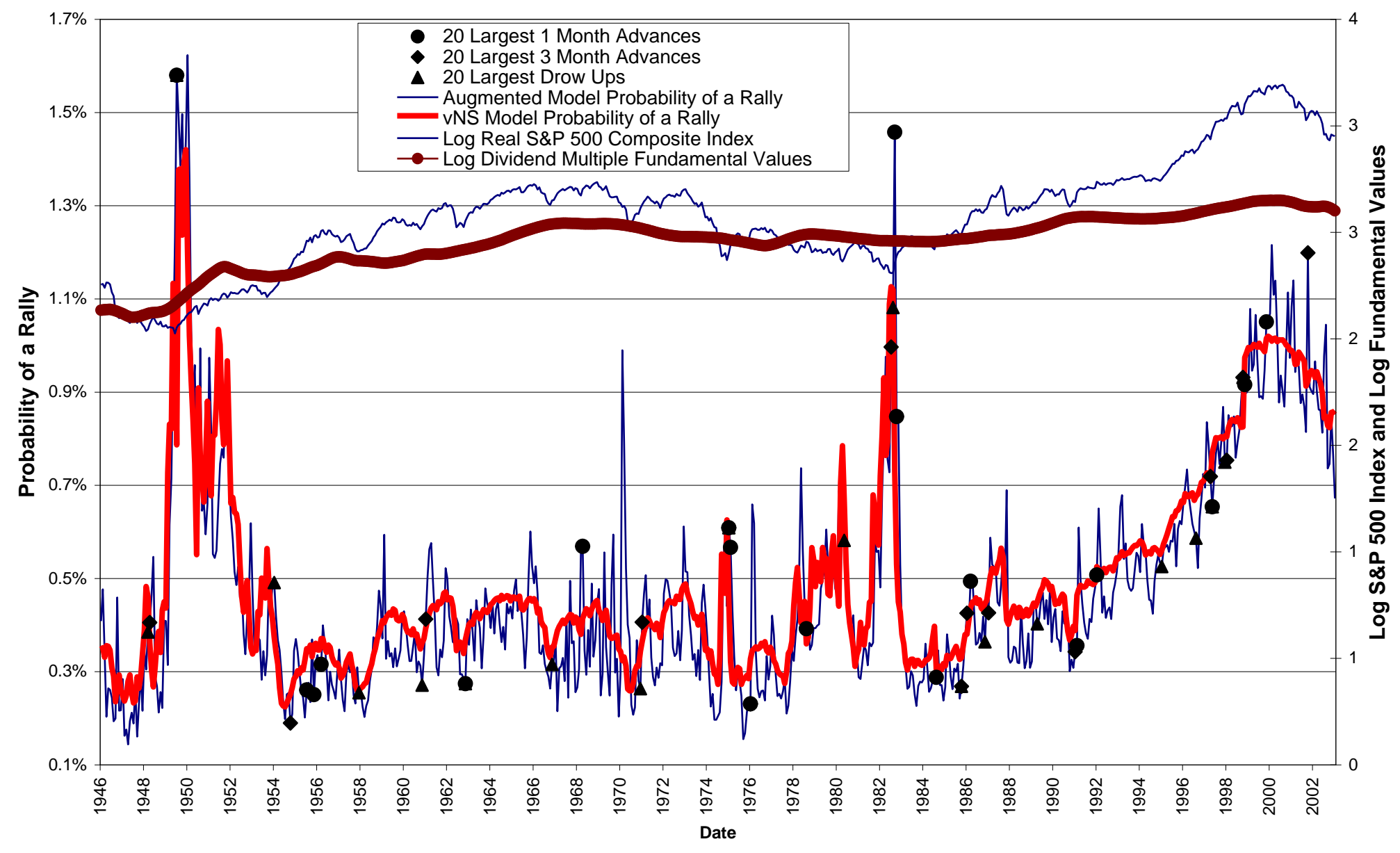


Figure 5:

Probabilities of a Crash from the vNS and the Augmented Model.

Campbell and Shiller Measure of Fundamental Values

January 1946 - January 2003

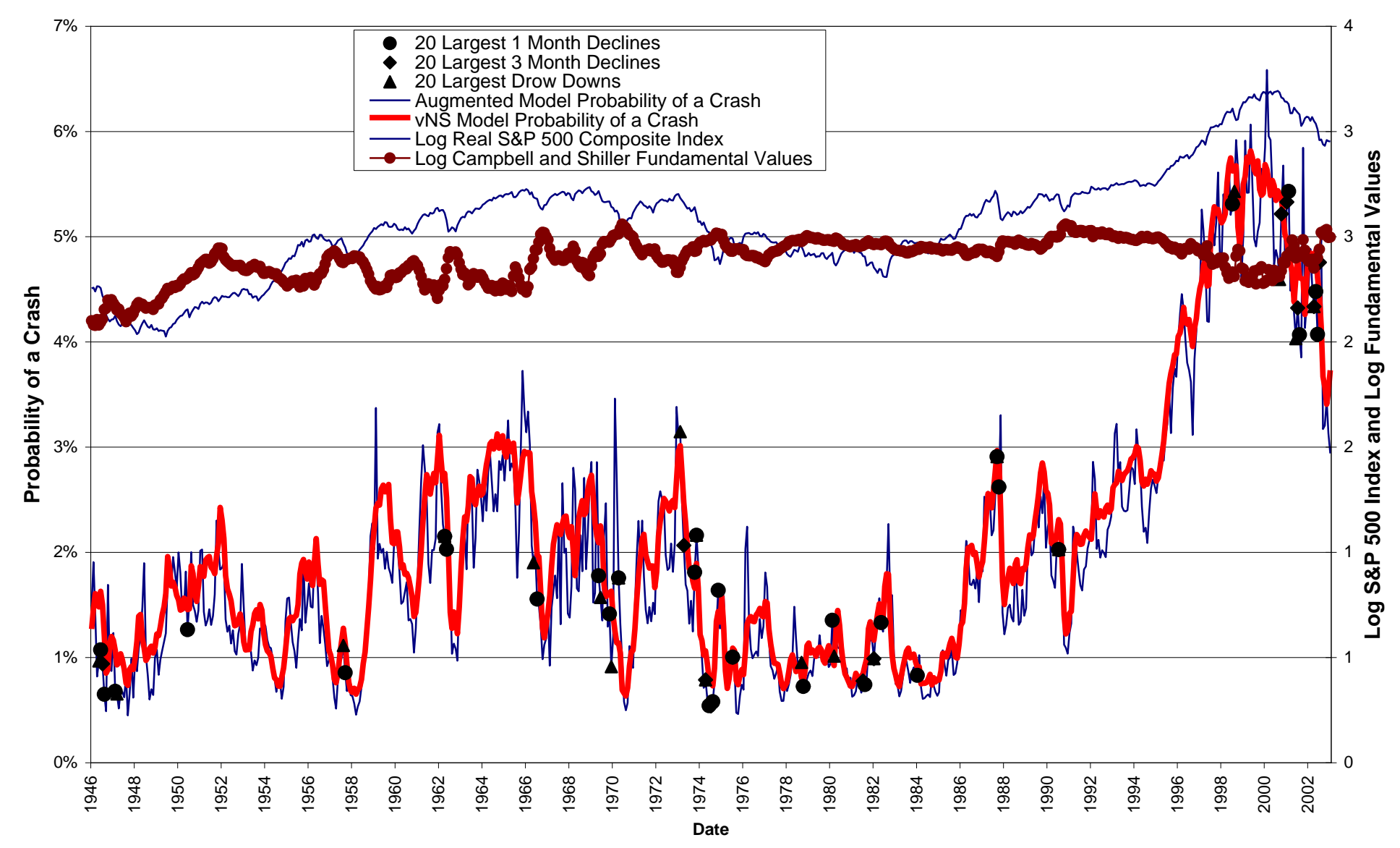


Figure 6:

Probabilities of a Rally from the vNS and the Augmented Model.

Campbell and Shiller Measure of Fundamental Values

January 1946 - January 2003

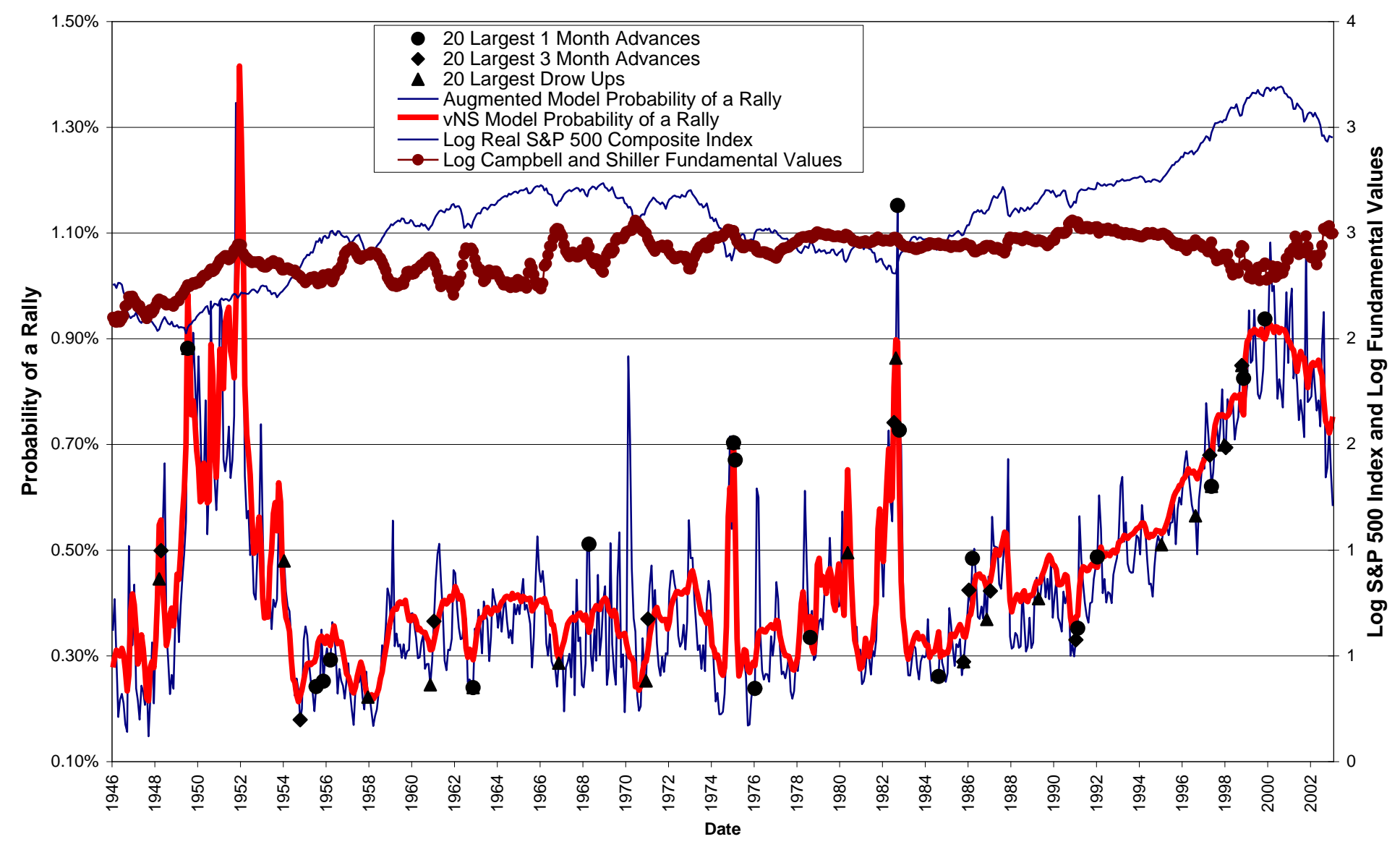




\section{Figure 7:}

Net Excess Wealth Generated Using the Augmented Speculative Bubble Model Trading Rule as a Percentage of the Buy and Hold Strategy Wealth. Dividend Multiple Measure of Fundamentals. January 1946 - January 2003

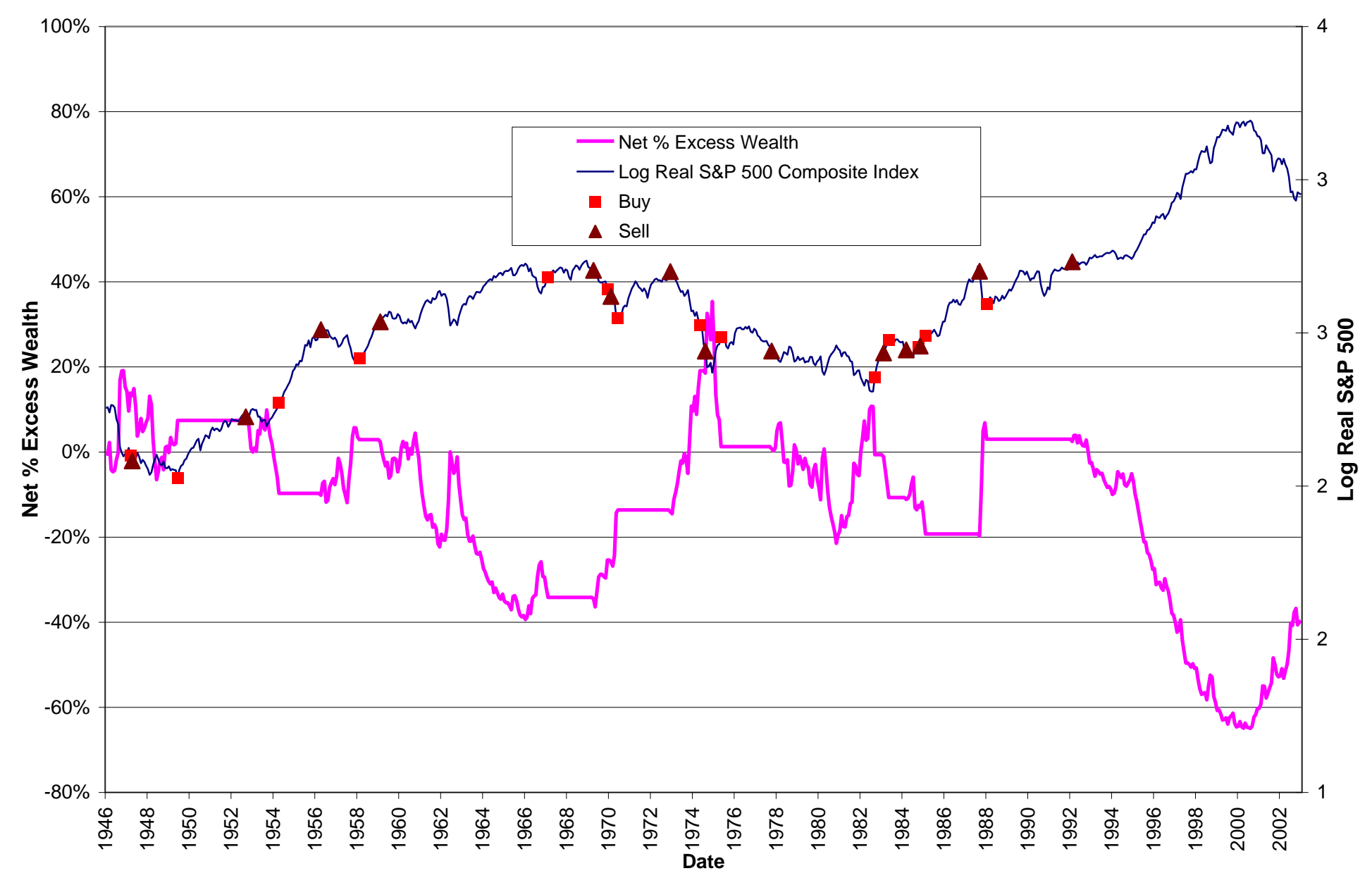




\section{Figure 8:}

Net Excess Wealth Generated Using the vNS Speculative Bubble Model Trading Rule as a Percentage of the Buy and Hold Strategy Wealth. Dividend Multiple Measure of Fundamentals. January 1946 - January 2003

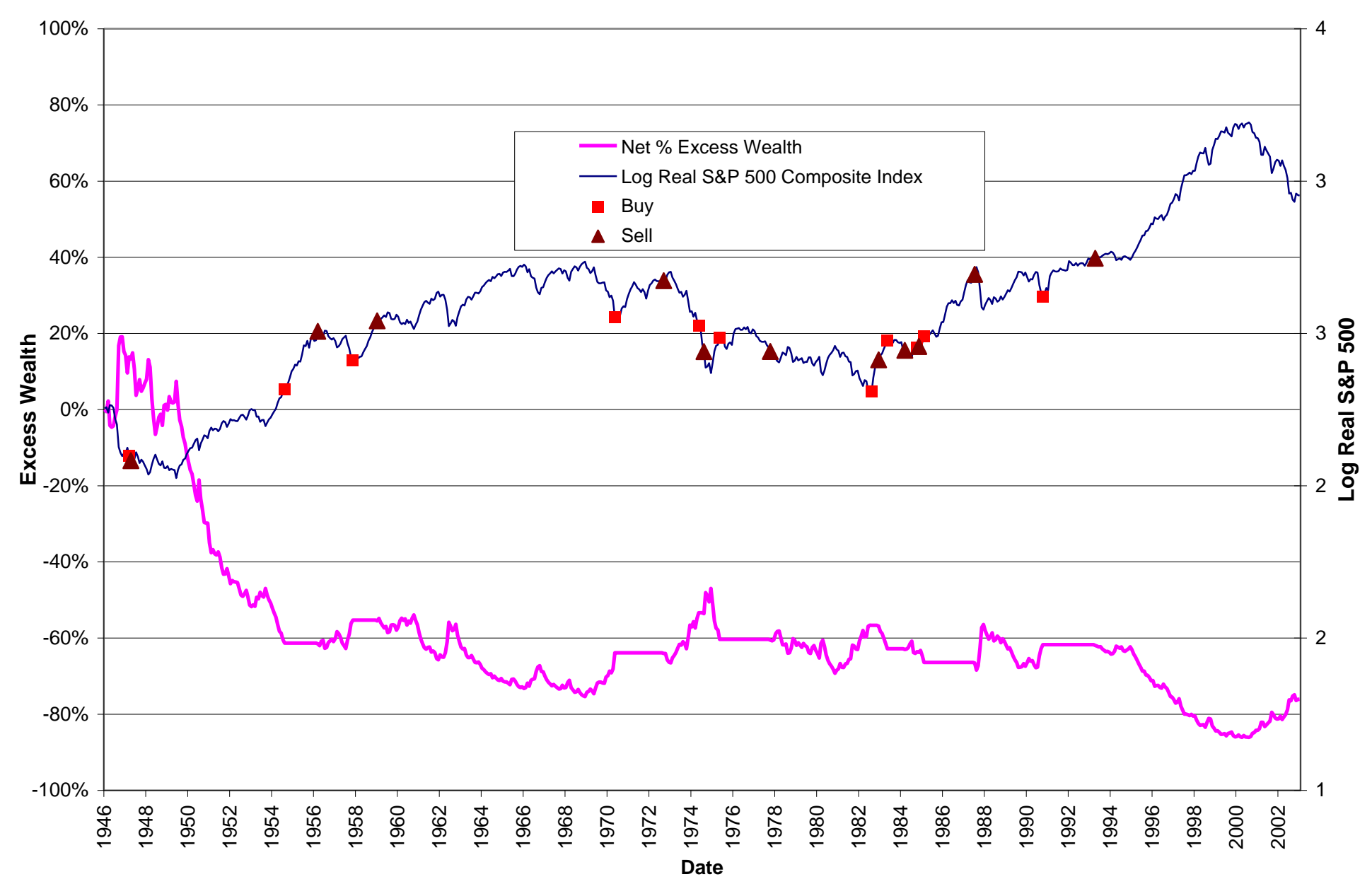




\section{Figure 9:}

Net Excess Wealth Generated Using the Augmented Speculative Bubble Model Trading Rule as a Percentage of the Buy and Hold Strategy Wealth. Campbell and Shiller (1987) Measure of Fundamentals. January 1946 - January 2003

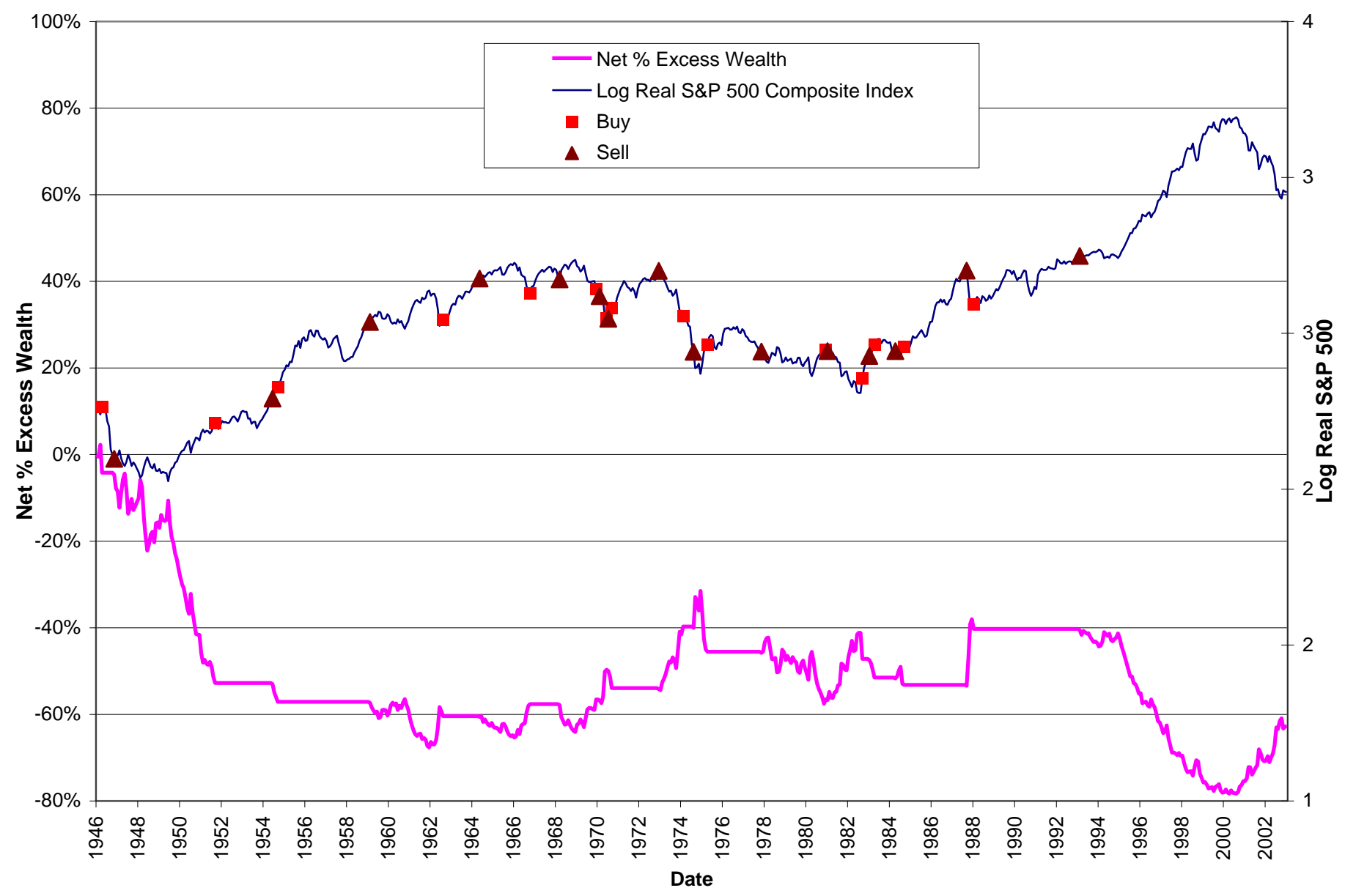




\section{Figure 10:}

Net Excess Wealth Generated Using the vNS Speculative Bubble Model Trading Rule as a Percentage of the Buy and Hold Strategy Wealth. Campbell and Shiller (1987) Measure of Fundamentals. January 1946 - January 2003

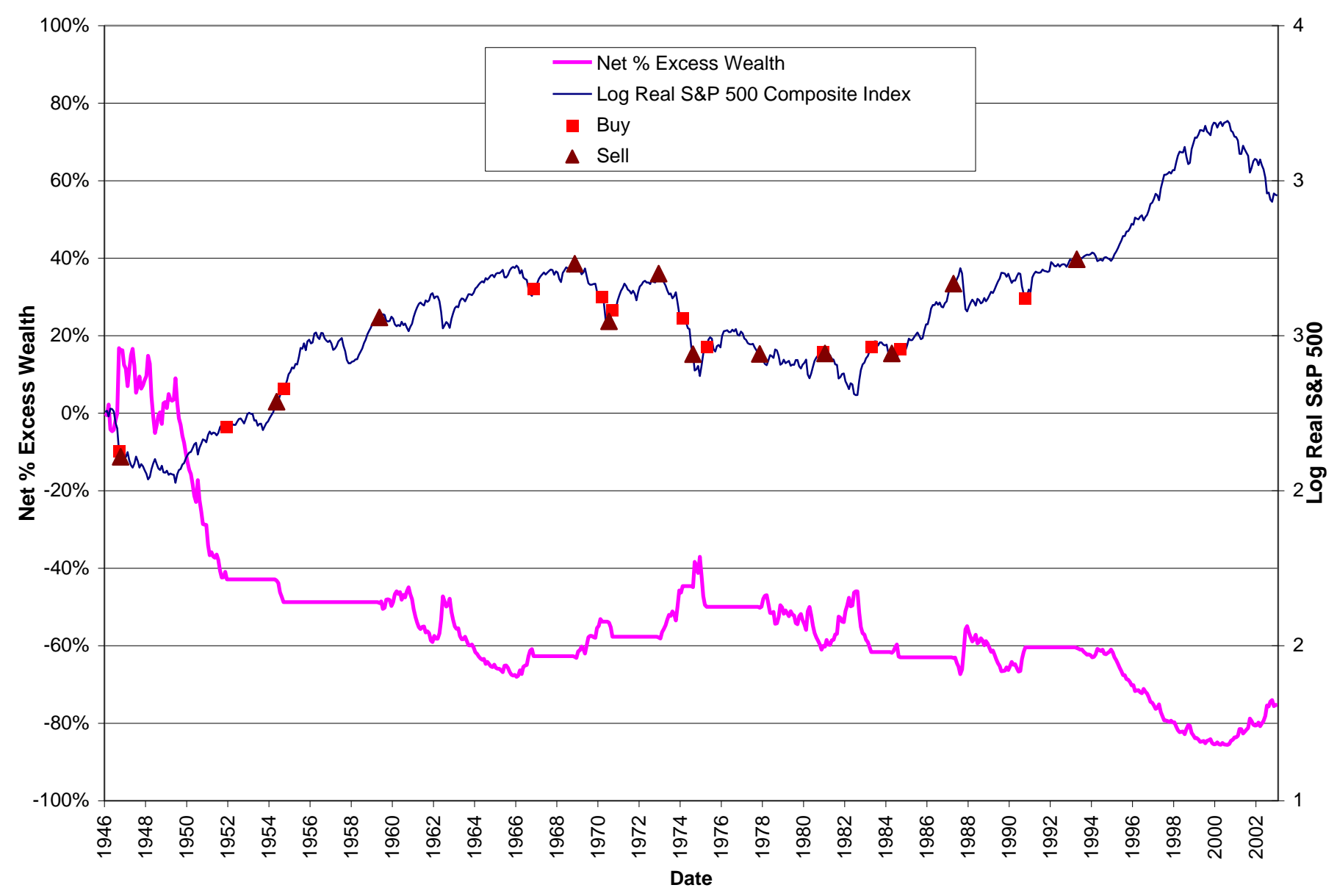


